Dear author,

Please note that changes made in the online proofing system will be added to the article before publication but are not reflected in this PDF.

We also ask that this file not be used for submitting corrections. 


\title{
Buckling of steel and Ni-Ti reinforcements in very high performance concrete (VHPC) elements
}

\author{
Javier Pereiro-Barceló ${ }^{a}$, José L. Bonet ${ }^{\mathrm{a}, *}$, José R. Albiol-Ibáñez ${ }^{\mathrm{b}}$ \\ ${ }^{a}$ Construction Engineering and Civil Engineering Projects Department, ICITECH, Universitat Politècnica de València, C/Vera Unnumbered, Valencia 46022, Spain \\ ${ }^{\mathrm{b}}$ DCAR (Architectonic Constructions Department), Universitat Politècnica de València, C/Vera Unnumbered, Valencia 46022, Spain
}

\section{H I G H L I G H T S}

- 10 VPHC columns with steel reinforcements were tested to study bar buckling.

- 2 VPHC and 2 HPC columns with Ni-Ti reinforcements were tested to study bar buckling.

- Columns with both Ni-Ti and steel reinforcements were compared.

- VHPC showed adequate to delay local buckling of compressed reinforcements.

- The model to evaluate bar buckling was extended to consider VHPC columns.

\section{A R T I C L E I N F O}

\section{Article history:}

Received 19 September 2017

Received in revised form 19 November 2017

Accepted 20 November 2017

Available online $\mathrm{xxxx}$

\section{Keywords:}

Buckling

Fibre-reinforced concrete

Very high performance concrete

High strength concrete

Shape memory alloy

$\mathrm{Ni}-\mathrm{Ti}$

\begin{abstract}
A B S T R A C T
Nowadays, the use of new materials is becoming increasingly common in the construction world due to their improved properties. High or Very High Performance Concrete (HPC or VHPC) and Shape Memory Alloys (SMA), specifically those composed of nickel and titanium (Ni-Ti), are some of these new materials. The low austenitic modulus of Ni-Ti as regards the elasticity modulus of steel (40-65 GPa instead of 200 GPa) can cause local buckling. In order to replace steel bars with Ni-Ti bars in reinforced concrete elements, it is convenient to use concrete with a high steel fibre content to delay local bar buckling. Hence employing either High Performance Concrete or VHPC may be appropriate, due to its composition with a high steel fibre content.

For all these reasons, VHPC elements with Ni-Ti reinforcements were studied. The results of an experimental campaign of VHPC columns are shown in this article. The VHPC columns were subjected to monotonic loading where the main goal was to study compressed steel reinforcement buckling. The results of these tests were also used to extend the mixed model proposed by Pereiro-Barceló and Bonet (2017), which determines the buckling critical stress for any transverse reinforcement separation and considers the effect of the concrete cover (with and without steel fibres). This model was recalibrated to consider elements made of VHPC. Besides, specimens made of either High Performance Concrete (HPC) or VHPC, and with Ni-Ti reinforcements, were also tested to study the behaviour of compressed Ni-Ti reinforcements in elements made of high strength fibre-reinforced concrete.
\end{abstract}

() 2017 Published by Elsevier Ltd.

\section{Introduction}

Compressed reinforcements buckling can reduce the expected ductility, which is why several research works on this matter are currently being conducted [1-4]. Accordingly, design codes limit tie spacing [5-8]. However, these codes do not take into account the positive effect of concrete with a fibres cover to delay buckling.

\footnotetext{
* Corresponding author.

E-mail addresses: japebar@upv.es (J. Pereiro-Barceló), jlbonet@cst.upv.es (J.L. Bonet), joalib1@csa.upv.es (J.R. Albiol-Ibáñez).
}

The cover of concrete with fibres can remarkably delay compressed reinforcements buckling depending on fibres content $[3,9,10]$. These authors proposed different methods to determine the critical buckling load of compressed reinforcements by taking into account the positive effect of the fibre-reinforced concrete cover. In his formulation, Dhakal [9] considered transverse reinforcement and the concrete cover placed discretely at the stirrups position. This method is valid for small tie spacings. Campione [10] considered both transverse reinforcement and concrete cover distributedly along the region involved in instability. This method is valid for both small and very large tie spacings. However, Pereiro-Barceló 


\section{Notation}

$f_{c} \quad$ nominal concrete compressive strength on cylindrical

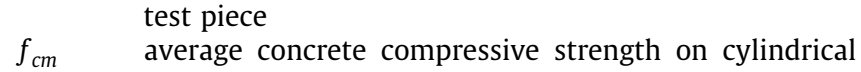

test piece

$E_{c} \quad$ concrete elasticity modulus

$\varepsilon_{c 85} \quad$ strain that corresponded to a stress of $0.85 f_{c m}$ denoted

after the peak load (measured on the softening branch)

$f_{L O P} \quad$ limit of proportionality in the flexural tensile strength

$f_{R, i} \quad$ residual tensile strengths

$f_{R, 1} \quad$ residual tensile strengths that correspond to the Crack Mouth Opening of $0.5 \mathrm{~mm}$

$f_{y} \quad$ yield stress of steel bar

$\varepsilon_{y} \quad$ the strain that corresponds to the yield stress of steel bar

$f_{s h} \quad$ stress at which the hardening branch begins of steel bar

$\varepsilon_{s h} \quad$ strain associated with $f_{\text {sh }}$

$f_{u} \quad$ maximum stress of steel bar

$\varepsilon_{u}$

$E_{s}$

$S$

$D$

$M_{S}$

$\mathrm{M}_{\mathrm{f}}$

strain associated with the maxil

elasticity modulus of steel bar

tie spacing of transversal reinforcement

diameter of the longitudinal reinforcement

temperature at which the transformation from austenite to martensite begins on cooling

ite to martensite finishes on cooling

$\mathrm{A}_{s} \quad$ temperature at which the transformation from martensite to austenite begins on heating

$\mathrm{A}_{\mathrm{f}} \quad$ temperature at which the transformation from martensite to austenite finishes on heating normalised vertical load

$\begin{array}{ll}v & \text { normalised vertical load } \\ N & \text { load applied by the hydraulic actuator }\end{array}$

$A_{c} \quad$ gross area of the section

$\varepsilon_{l} \quad$ longitudinal reinforcement strain in the zone where compressed bar instability took place
$\Delta \quad$ displacement at the midspan of the specimen

$L_{\text {tot }} \quad$ distance between load hinges of the specimen

$N_{\max } \quad$ maximum applied axial load

$N_{c}$ applied axial load in the instability situation of compressed bar

$\Delta_{c} \quad$ horizontal displacement at midspan of specimen in the instability situation of compressed bar

$\varepsilon_{\text {crit }}$ compressed bar strain in the instability situation of compressed bar

$\varepsilon_{c r i t, \eta \leqslant 1}$ buckling strain of the compressed bar that buckle between the stirrups

$\sigma_{\text {crit }}$ compressed bar stress in the instability situation of compressed bar

$\varepsilon_{\text {crit,model }}$ critical compressed bar strain calculated with the mixed model

$\sigma_{\text {crit }} \quad$ critical compressed bar stress calculated with the mixed model

$E_{r} \quad$ reduced modulus of the longitudinal reinforcement

I inertia moment of longitudinal reinforcement

A transverse reinforcement area

$c_{c} \quad$ critical adimensional stress

$\alpha_{s} \quad$ transverse reinforcement axial stiffness

$\alpha_{s, y} \quad$ transverse reinforcement axial stiffness on the plastic branch

$\alpha_{c} \quad$ concrete cover axial stiffness

$\gamma \quad$ relation between transverse reinforcement axial stiff-

ness $\alpha_{s}$ and the bending stiffness of longitudinal bar $E_{r} I$

$k_{c s} \quad$ relation between concrete cover axial stiffness $\alpha_{c}$ and transverse reinforcement axial stiffness $\alpha_{s}$

$E_{S w} \quad$ tangent modulus of transverse reinforcement

$A_{s w} \quad$ transverse reinforcement area

$L_{e f} \quad$ effective transverse reinforcement length

$\eta \quad$ relation between length of the longitudinal bar where compressed bar instability takes place and transverse reinforcement separation and Bonet [3] considered the concrete cover distributedly and transverse reinforcement discretely, which is why this model is valid for any tie spacing. These authors also considered the degradation of the concrete cover. Their proposed model was calibrated for normal strength concrete (NSC), with and without fibres.

Due to the fact that concretes with fibres delay buckling, VHPC can be a suitable concrete for this purpose because it has a high fibre content [11]. In addition, its high strength confers more adherence to fibres with the concrete matrix. Its strength oscillates between 100 and $150 \mathrm{MPa}$ [12], it shows high ductility on the postpeak branch under compression [13], and it develops high flexural tensile strength [12] and high strength and ductility under direct tension [12] compared with either Fibre-Reinforced Normal Strength Concrete (FRNSC) or Fibre-Reinforced High Strength Concrete (FRHSC), which is also called High Performance Concrete (HPC). Several authors have concluded that using concretes with fibres, specially VHPC, could increase the ductility of elements [14-20].

At the same time, several research works [21,22] have studied the possibility of replacing steel longitudinal bars with shape memory alloy (SMA) nickel - titanium based (Ni-Ti) in the critical zones of structures. The aim here is to reduce residual displacements, increase ductility and to gain an energy dissipator element. $\mathrm{Ni}-\mathrm{Ti}$ alloys are materials characterized by changing into two crystallographic phases, austenite and martensite, by their temperature or stress-strain state being modified. This fact explains the two main properties of Ni-Ti: shape memory effect and superelas- ticity. Shape memory is the phenomenon by which Ni-Ti changes its crystallographic phase after heating and can recover a predefined shape. Superelasticity is observed when, starting in the austenite phase, martensite is induced by stress increment. When stress disappears, the austenite phase is recovered, as is its original shape [23-26]. These two properties, and their high ductility and damping capacity, make Ni-Ti a suitable material to be applied in structural engineering [27-36]. Nonetheless, the elasticity modulus of this material (between 40 and $60 \mathrm{GPa}$ ) is approximately 3 and 4 times lower than conventional steel (200 GPa), which can result in local bar buckling. This phenomenon has not been studied much for Ni-Ti. Only tests on isolated Ni-Ti bars subject to compression are available. Rahman et al. [37] and Rahman and Tani [38] tested Ni-Ti wires ( $2 \mathrm{~mm}$ diameter) under compression and concluded that the bars showed two instability points. After buckling, the Ni-Ti bars were able to elevate the supported load because stiffness increased when the Ni-Ti reached the martensitic region. Finally, the bar reached a second instability point and the supported load decreased due to second-order effects. PereiroBarceló and Bonet [4] tested $12 \mathrm{~mm}$-diameter bars and also found two instability points in the least slender specimens. They proposed a method to modify the constitutive equation under compression of SMA bars to consider buckling according to on an analytical procedure and experimental results.

One possible solution for delaying the buckling of compressed reinforcements in concrete elements is to use concrete with steel fibres. In addition, as the strain at which the martensitic transfor- 
mation branch begins $\left(\varepsilon_{A}\right)$ in Ni-Ti bars is around $4-8 \%$, concrete with high ductility is required to reach $\varepsilon_{A}$ without causing any significant loss in its strength. For this reason, the use of concrete with a high steel fibre content, such as HPC or VHPC, may be suitable. Both concrete types are being more widely used in structural elements [39-44]. For this reason, one of the aims of this article is to study the buckling of steel reinforcements in VHPC elements. To achieve this, an experimental campaign was carried out. This experimental campaign consisted of VHPC columns with steel reinforcements. The experimental results were used to extend the mixed model proposed by Pereiro-Barceló and Bonet [3] to consider this concrete type. Besides, the interest in using Ni-Ti bars is currently increasing because of their aforementioned properties. Therefore, another aim of this article is to experimentally study the buckling of Ni-Ti reinforcements in VHPC and HPC elements.

\section{Experimental programme}

The aim of the tests was to study the behaviour of compressed bars in both VHPC and HPC elements with both steel and Ni-Ti reinforcements. Another aim was to provide results to extend the mixed model of Pereiro-Barceló and Bonet [3] to take into account elements made of VHPC.

\subsection{Specimens}

Fourteen bone-shaped reinforced concrete columns were tested. The geometry and reinforcing details are shown in Fig. 1. The length of the columns was $1.35 \mathrm{~m}$, the central cross-section was squared on the $0.2 \mathrm{~m}$ side and the end cross-sections were $0.4 \times 0.2 \mathrm{~m}$. Columns were subjected to an eccentric compressive load.
The tests were designed to produce column failure because of the compression of concrete without developing high plastic strains in the tensioned reinforcement. For this reason, the longitudinal reinforcement was not symmetric to the bending axis. The longitudinal reinforcements were $12 \mathrm{~mm}$ in diameter on the compressed side and $16 \mathrm{~mm}$ in diameter on the tensioned side. For specimens with SMA reinforcements, only the 12-mm compressed reinforcements were made of SMA (Fig. 2), and the rest were made of steel.

In the experimental programme, each studied parameter ranges was as follows:

- Concrete strength $\left(\mathrm{f}_{\mathrm{c}}\right)$ : nominal strengths of $80 \mathrm{MPa}(\mathrm{HPC})$ and $120 \mathrm{MPa}$ (VHPC) were chosen.

- Steel - fibre content: the fibre content was $80 \mathrm{~kg} / \mathrm{m}^{3}$ for HPC and $150 \mathrm{~kg} / \mathrm{m}^{3}$ for VHPC, which corresponded to volumetric steel/fibre ratios of $1 \%$ and $1.9 \%$, respectively. How a high fibre content allowed a delay in the local buckling of reinforcements was studied.

- Fibre type: for HPC, a single type of fibres, long (slenderness of 80 , length of $30 \mathrm{~mm}$ ) was used, whereas two fibre types were analysed for VHPC: the first was composed only of long fibres

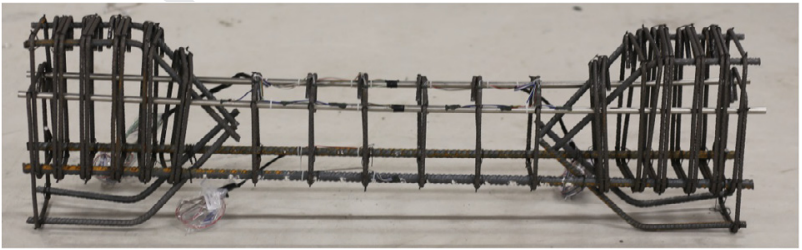

Fig. 2. Reinforcement arrangement of the specimens with Ni-Ti compressed bars.

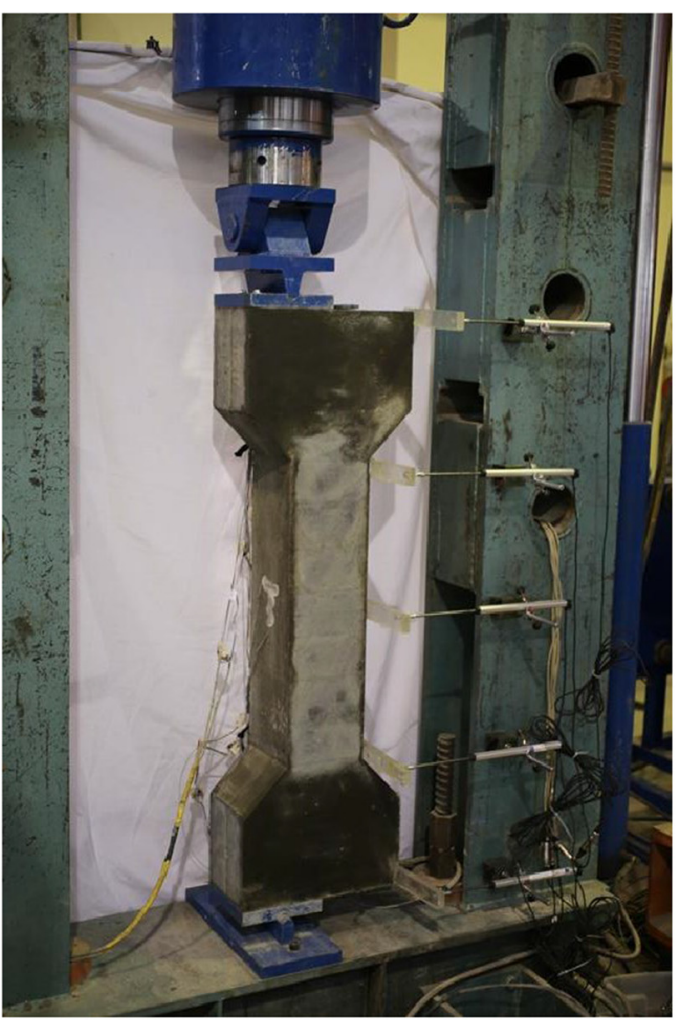

(a)

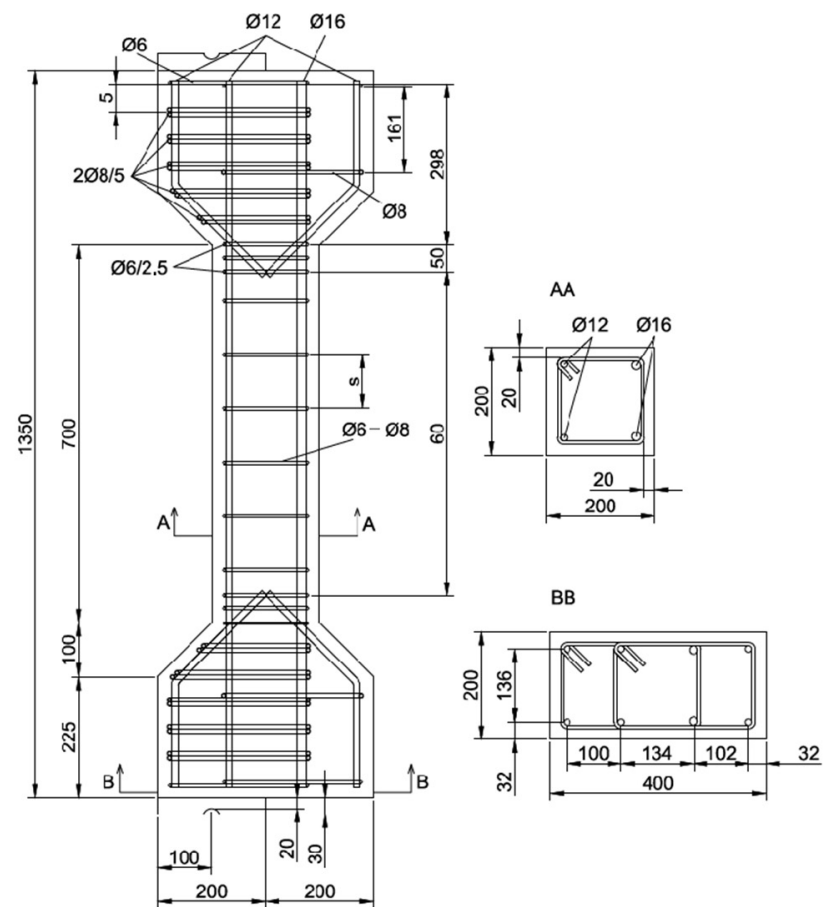

(b)

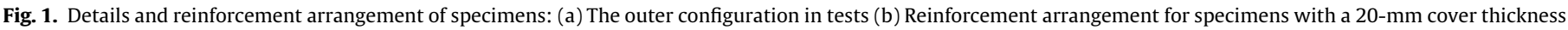
up to ties (units in $\mathrm{mm}$ ).

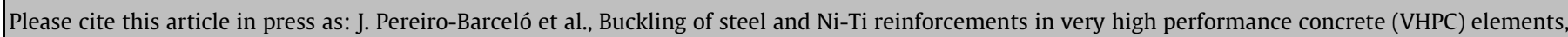
Constr. Build. Mater. (2017), https://doi.org/10.1016/j.conbuildmat.2017.11.113 
(slenderness of 80 , length of $30 \mathrm{~mm}$ ). The second, which is called mixed, was composed of $60 \mathrm{~kg} / \mathrm{m}^{3}$ of long fibres and $90 \mathrm{~kg} / \mathrm{m}^{3}$ of short fibres (slenderness of 26 , length of $13 \mathrm{~mm}$ ). We analysed how fibre combination type could affect critical buckling strain of the bar.

- Type of bar: two types of materials were analysed for compressed reinforcements: steel and $\mathrm{Ni}-\mathrm{Ti}$ with superelasticity. The other reinforcements were made of steel.

- Concrete cover: for the elements made of HPC, the geometric cover up to the stirrup was fixed at $2 \mathrm{~cm}$, whereas two covers were studied in the elements made with VHPC: $1 \mathrm{~cm}$ and 2 $\mathrm{cm}$. We analysed whether the stiffness provided by the fibreconcrete cover depended on cover thickness.

- Tie spacing: for the specimens with compressed reinforcements made of $\mathrm{Ni}-\mathrm{Ti}$, spacings were $5 \mathrm{~cm}$ and $10 \mathrm{~cm}$. For the specimens with compressed reinforcements made of steel, spacings were $10 \mathrm{~cm}, 30 \mathrm{~cm}$ and $60 \mathrm{~cm}$. Therefore for $\mathrm{Ni}-\mathrm{Ti}$, two $\mathrm{s} / D$ ratios were considered, 4.16 and 8.33 , where $s$ is the tie spacing and $D$ is the diameter of the longitudinal reinforcement (12 $\mathrm{mm}$ ). For steel, three $s / D$ ratios were contemplated: 8.33, 25 and 5 . The $s / D$ ratios range of the $\mathrm{Ni}$-Ti bars was lower than the steel range because the austenite modulus of $\mathrm{Ni}-\mathrm{Ti}$ was between 3 and 4 times lower than the elasticity modulus of steel. Consequently, lesser tie spacing was required to delay buckling. The $s / D=4.16$ ratio was lower than the maximum ratio proposed by EN 1998-1:2004 [6] for high ductility columns (DHC), or by ACI318R-14 [8] for special frames, which is $s / D=6$ in both codes. The $s / D=8.33$ ratio approximately equalled the ratio proposed by EN 1988-1:2004 [6] for medium ductility (DCM) columns or by ACI-318R-14 [8] for ordinary frames, which is $s / D=8$ in both codes. Finally, the $s / D=25$ ratio or the $s / D=50$ ratio was higher than the ratio stated in EN 1992-1:2004 [45], whose maximum value is $s / D=20$. The objective of these last cases was to analyse the delay in reinforcement buckling thanks to the steel fibres in VHPC elements with no transverse reinforcement contribution.

Table 1 shows details of the specimens. Specimens designation is: (SMA)-X-ySyTz, where "SMA" is present only in the specimens with compression reinforcements of $\mathrm{Ni}-\mathrm{Ti}$, " $\mathrm{x}$ " denotes type of concrete (HPC or VHPC), " $y$ " reflects the fibre type (L for long or M for mixed), " $y$ " is the tie spacing $(5,10,30,60 \mathrm{~cm})$ and " $z$ " represents the geometric cover of the compressed reinforcement $(1,2 \mathrm{~cm})$.

Behaviour of the Ni-Ti bars under compression with two fibrereinforced concrete types (HPC and VHPC) were studied as these concretes are probably suitable for use with $\mathrm{Ni}$-Ti bars for the following reasons:
1. Ni-Ti bars have an elasticity modulus that is approximately between 3 and 4 times lower than steel. Consequently, if the cover becomes ineffective, Ni-Ti bars buckle before steel bars do. Bar buckling can be delayed either by reducing the tie spacing or using a concrete with steel fibres. In this case, the second option was chosen because the first option may imply a small tie spacing and, consequently, problems with casting-in-place concrete.

2. Ni-Ti reinforcements should be able to enter the martensitic transformation branch for two reasons: to provide the structure with ductility when plastic hinges are generated; Ni-Ti bars act as energy dissipators during load - unload processes. As the NiTi elasticity modulus is lower than steel, a concrete with a high ductility is required under both tension and compression. Accordingly, HPC and VHPC are the most adequate.

3. HPC and VHPC were also chosen because their combination with $\mathrm{Ni}$-Ti reduces damage in the critical zone of the structure, and the residual strains are reduced during load-unload processes [22].

\subsection{Material characterization}

The concretes used were HPC, with a nominal strength of 80 MPa under compression, and VHPC, which a nominal strength of $120 \mathrm{MPa}$ under compression. Both HPC and VHPC were selfcompacting concretes. Self-compacting concrete was used to facilitate the cast into the formwork because of its low water/cement ratio and its high fibre content. The dosage of both concretes is shown in Table 2. The steel fibres were DRAMIX 80/30 BP, which had a hooked end, and was $30 \mathrm{~mm}$ long and diameter $0.5 \mathrm{~mm}$, with a slenderness (L/d) of 80, a yield stress of $3070 \mathrm{MPa}$ and an elasticity modulus of $200 \mathrm{GPa}$. The other type of fibre was DRAMIX $13 / 0.16$, with a straight geometry, and was $13 \mathrm{~mm}$ long, diameter $0.16 \mathrm{~mm}$, a slenderness (L/d) of 81.25 , a yield stress of $2750 \mathrm{MPa}$ and an elasticity modulus of $200 \mathrm{GPa}$.

Table 1 displays the concrete characterisation results. The average cylinder compressive strength of concrete of each support $\left(f_{c m}\right)$, the concrete elasticity modulus $E_{c}$ and the strain that corresponded to a stress of $0.85 f_{c m}$ denoted after the peak load (measured on the softening branch) $\varepsilon_{c 85}$, were obtained as the average of three cylindrical control specimens, which measured $150 \times$ $300 \mathrm{~mm}$ (UNE-EN 12390-3 [46]). For the mechanical characterization of flexural strength, a three-point test was conducted on prismatic control specimens $(550 \times 150 \times 500 \mathrm{~mm})$ according to UNE EN 14651:2007 [47]. The concrete flexural properties are also shown in Table 1, where: $f_{L O P}$ is the limit of proportionality in the flexural tensile strength test, and $f_{R, 1}, f_{R, 2}, f_{R, 3}$ and $f_{R, 4}$ are the

Table 1

Details of test specimens.

\begin{tabular}{|c|c|c|c|c|c|c|c|c|c|c|c|}
\hline Specimen & $\begin{array}{l}\mathrm{s} \\
(\mathrm{cm})\end{array}$ & $\begin{array}{l}\text { Concrete cover thickness } \\
(\mathrm{cm})\end{array}$ & $\begin{array}{l}\phi_{t} \\
(\mathrm{~mm})\end{array}$ & Batch & $\begin{array}{l}\mathrm{f}_{\mathrm{cm}} \\
(\mathrm{MPa})\end{array}$ & $\begin{array}{l}\mathrm{E}_{\mathrm{c}} \\
(\mathrm{MPa})\end{array}$ & $\begin{array}{l}\mathrm{f}_{\mathrm{LOP}} \\
(\mathrm{MPa})\end{array}$ & $\begin{array}{l}\mathrm{f}_{\mathrm{R}, 1} \\
(\mathrm{MPa})\end{array}$ & $\begin{array}{l}\mathrm{f}_{\mathrm{R}, 2} \\
(\mathrm{MPa})\end{array}$ & $\begin{array}{l}\mathrm{f}_{\mathrm{R}, 3} \\
(\mathrm{MPa})\end{array}$ & $\begin{array}{l}\mathrm{f}_{\mathrm{R}, 4} \\
(\mathrm{MPa})\end{array}$ \\
\hline VHPC-Ms10T2 & 10 & 2 & 6 & 2 & 123.68 & 43222 & 11.84 & 22.78 & 20.74 & 11.59 & 7.02 \\
\hline VHPC-Ms30T2 & 30 & 2 & 6 & 2 & 123.48 & 42500 & 11.74 & 22.99 & 21.75 & 11.71 & 7.23 \\
\hline VHPC-Ms60T2 & 60 & 2 & 6 & 1 & 126.39 & 39566 & 10.29 & 17.72 & 11.32 & 5.00 & 3.83 \\
\hline VHPC-Ms10T1 & 10 & 1 & 6 & 2 & 124.05 & 44187 & 9.87 & 17.01 & 20.17 & 12.45 & 9.35 \\
\hline VHPC-Ms60T1 & 60 & 1 & 6 & 1 & 131.11 & 43821 & 10.21 & 18.55 & 20.14 & 12.78 & 9.75 \\
\hline VHPC-Ls10T2 & 10 & 2 & 8 & 3 & 117.92 & 44331 & 11.16 & 22.24 & 25.57 & 25.32 & 22.03 \\
\hline VHPC-Ls30T2 & 30 & 2 & 6 & 2 & 114.86 & 43472 & 6.28 & 22.18 & 24.69 & 22.54 & 11.45 \\
\hline VHPC-Ls60T2 & 60 & 2 & 6 & 1 & 113.07 & 44000 & 10.42 & 19.87 & 20.68 & 13.56 & 9.46 \\
\hline VHPC-Ls10T1 & 10 & 1 & 6 & 2 & 125.96 & 42276 & 11.00 & 23.89 & 24.58 & 14.33 & 8.23 \\
\hline VHPC-Ls60T1 & 60 & 1 & 8 & 3 & 105.00 & 40029 & 7.67 & 12.44 & 12.56 & 10.83 & 9.21 \\
\hline SMA-HPC-Ls05T2 & 5 & 2 & 8 & 3 & 78.73 & 38655 & 7.78 & 14.05 & 16.76 & 15.59 & 12.09 \\
\hline SMA-HPC-Ls10T2 & 10 & 2 & 8 & 3 & 83.86 & 38373 & 7.56 & 13.36 & 15.29 & 14.32 & 11.46 \\
\hline SMA-VHPC-Ls05T2 & 5 & 2 & 8 & 3 & 107.16 & 44221 & 9.02 & 15.44 & 16.07 & 13.98 & 9.95 \\
\hline SMA-VHPC-Ls10T2 & 10 & 2 & 8 & 3 & 115.4 & 43293 & 10.52 & 18.65 & 19.94 & 18.82 & 15.12 \\
\hline
\end{tabular}


Table 2

Concrete doses $\left(\mathrm{kg} / \mathrm{m}^{3}\right)$

\begin{tabular}{|c|c|c|c|c|c|c|c|c|c|c|c|}
\hline Description & Cement & Water & $\begin{array}{l}\text { Gravel }\left(D_{\max }\right. \\
6 \mathrm{~mm})\end{array}$ & $\begin{array}{l}\text { Sand }\left(D_{\max }\right. \\
6 \mathrm{~mm})\end{array}$ & $\begin{array}{l}\text { Sand }\left(\mathrm{D}_{\max }\right. \\
0.8 \mathrm{~mm}) \\
A F_{-} T \_0 / 8 \_S\end{array}$ & $\begin{array}{l}\text { Sand }\left(D_{\max }\right. \\
0.4 \mathrm{~mm}) \\
A F \_T \_0 / 4 \_\end{array}$ & $\begin{array}{l}\text { Lime-stone } \\
\text { filler }\end{array}$ & $\begin{array}{l}\text { Silica } \\
\text { fume }\end{array}$ & $\begin{array}{l}\text { Steel fibres } \\
\text { DRAMIX } \\
80 / 30 \text { BP }\end{array}$ & $\begin{array}{l}\text { Steel fibres } \\
\text { DRAMIX } \\
13 / 0.16\end{array}$ & $\begin{array}{l}\text { Super- } \\
\text { plasticizer }\end{array}$ \\
\hline HPC & 525 & 196 & 450 & 1045 & & & 200 & & 80 & & 8.13 \\
\hline VHPC type 1 & 1000 & 177 & & & 575 & 310 & & 150 & 150 & & 29 \\
\hline VHPC type 2 & 1000 & 177 & & & 575 & 310 & & 150 & 60 & 90 & 29 \\
\hline
\end{tabular}

residual tensile strengths that correspond to the Crack Mouth Opening (CMOD) of $0.5,1.5,2.5$ and $3.5 \mathrm{~mm}$, respectively (UNE EN 14651:2007 [47]).

For the steel reinforcement characterization, three different steel batches were used because the specimens were fabricated at different periods of time. Table 3 depicts the results of the characterization tests run under direct tension (UNE EN-10002-1 [48]) for both the longitudinal and transverse steel reinforcements. In Table $3, f_{y}, \varepsilon_{y}, f_{s h}, \varepsilon_{s h}, f_{u}, \varepsilon_{u}, E_{s}$, are respectively the yield stress, the strain that corresponds to the yield stress, the stress at which the hardening branch begins, the strain associated with $f_{s h}$, the maximum stress, the strain associated with the maximum stress and the elasticity modulus. The displayed values are the average of two characterization tests for each diameter. For those specimens made with batches 1 and 2, the stirrup diameter was 6 $\mathrm{mm}$, and it was $8 \mathrm{~mm}$ for those made with batch 3 .

In the engineering field, symmetry is assumed in the constitutive equation of steel; that is, the stress-strain relationship under compression is the same as in tension, but with a contrary sign. Nonetheless, experimental research into monotonic loads has verified that asymmetry exists in the stress-strain relationship [49]. This behaviour is caused because the reinforcement area increases when the bar is compressed due to the Poisson effect. In order to take this difference into account in behaviour, and in order to keep considering the same area in tension and compression from the engineering point of view, Dodd and Restrepo-Posada [49] proposed the following expressions to transform the constitutive relation under tension $(\sigma-\varepsilon)$ to compression $\left(\sigma^{\prime \prime}-\varepsilon^{\prime \prime}\right)$ :

$\sigma^{\prime \prime}=-\sigma \cdot(1+\varepsilon)^{2}$

$\varepsilon^{\prime \prime}=-\frac{\varepsilon}{1+\varepsilon}$
Table 3 shows the mechanical characteristics of the reinforcements under tension and under compression. The characteristics under compression were obtained by using Expressions (1) and (2), proposed by Dodd and Restrepo-Posada [49] (it should be noted that the signs did not change in either stresses or strains).

$\mathrm{Ni}$-Ti bars were provided by the supplier and had a polished surface. Differenced Scanning Calorimetry (DSC) tests were performed to determine the four transformation temperatures $\left(A_{s}\right.$ and $A_{f}$ for the beginning and the end of the austenitic transformation, $M_{s}$ and $M_{f}$ for the beginning and the end of the martensitic transformation) according to code ASTM F2004-05 [50]. These four values govern the four stresses of the hysteresis cycle of SMA. The transformation temperatures were: $M_{f}=-49.15^{\circ} \mathrm{C}, M_{s}=-31.23$ ${ }^{\circ} \mathrm{C}, A_{s}=-20.75^{\circ} \mathrm{C}$ and $A_{f}=-7.70^{\circ} \mathrm{C}$. Ni-Ti was also mechanically characterised by direct tension and compression tests at a room temperature of $27-30^{\circ} \mathrm{C}$ : Young's modulus under tension was $64647 \mathrm{MPa}$. The forward martensitic transformation under tension at room temperature began at a stress of $450 \mathrm{MPa}$. According to Fig. 3, the provided bars were not completely superelastic because of the magnitude of the residual strains. Unlike steel, Ni-Ti exhibited a different tension-compression behaviour [51,52]. Fig. 3 shows the stress-strain curve of the Ni-Ti bars at room temperature under both tension and compression. Young's modulus under compression was the same as under tension. The forward martensitic transformation under compression at room temperature also began at a stress of $450 \mathrm{MPa}$. The final martensitic transformation strain under compression at room temperature was $4.5 \%$, which coincided with a stress of $710 \mathrm{MPa}$. The martensitic modulus branch under compression at room temperature was $28125 \mathrm{MPa}$. The plastic branch started at a stress of $1150 \mathrm{MPa}$. A detailed description of the compressive and tensile tests of these bars are displayed in Pereiro-Barceló and Bonet [4]. Pereiro-Barceló and

Table 3

Mechanical properties of reinforcements.

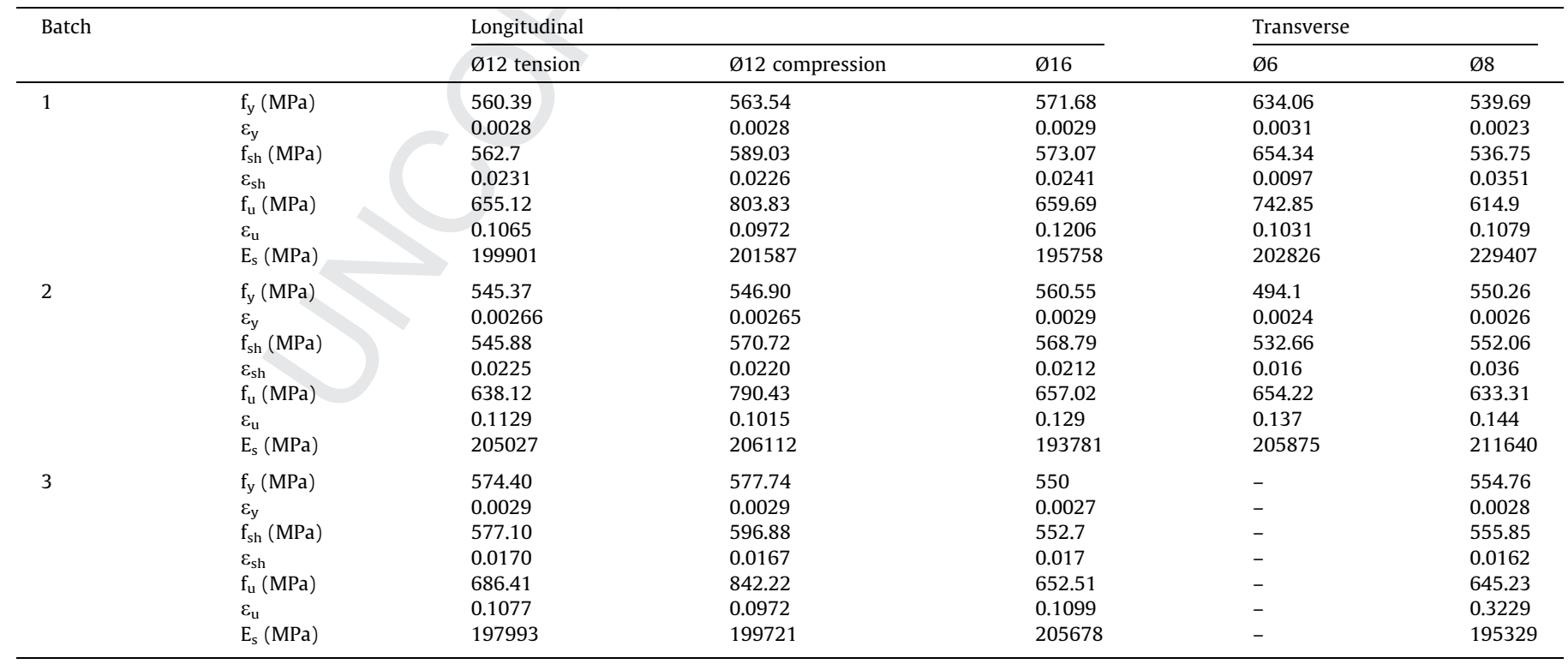




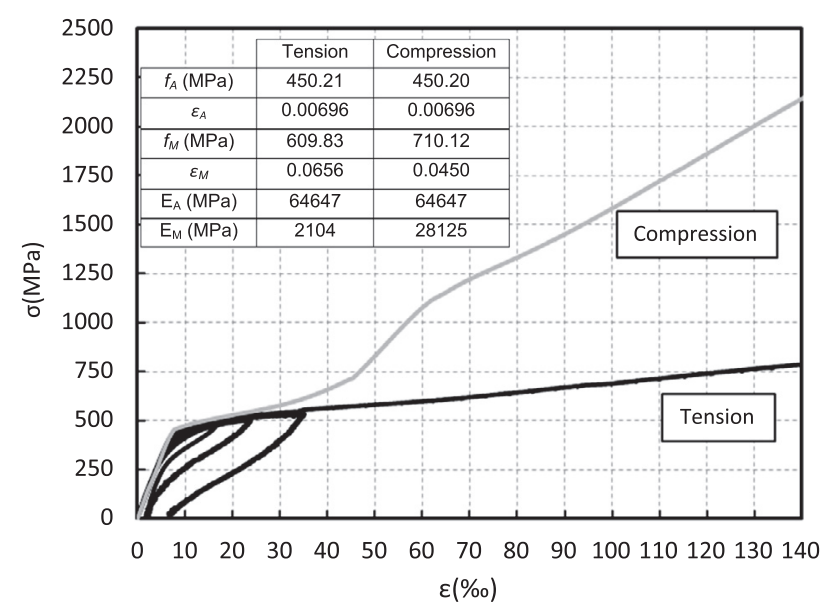

Fig. 3. Mechanical properties of Ni-Ti bars.

Bonet [4] analysed inelastic buckling behaviour of these bars outside concrete with various slenderness ratios.

\subsection{Test setup}

The boundary conditions of specimens were hinges on the ends, achieved by screwing two plaques onto the ends of columns. Each plaque had a groove. The free length between hinges was $1.39 \mathrm{~m}$. Load was applied through knife edges seated in these grooves, with an eccentricity of $0.10 \mathrm{~m}$ on both sides. A $2500 \mathrm{kN}$ hydraulic actuator was employed. Tests were run by applying the displacement control to the midspan section at a speed of $0.2+1-0.05 \mathrm{~mm} / \mathrm{min}$.

\subsection{Instrumentation}

The instruments used were as follows: strain gauges at longitudinal and transverse reinforcements, a photogrammetric system, linear voltage displacement transductors (LVDTs) and thermocouples for the Ni-Ti bars.

Gauges were placed in the compressed and tensioned reinforcements equidistantly between the stirrups for tie spacings of 5 and $10 \mathrm{~cm}$. For the 30 and $60 \mathrm{~cm}$ spacings, gauges were placed every 5 $\mathrm{cm}$. The gauges of the tensioned reinforcements were placed on the perpendicular plane to the bending axis in order to not measure the local effects of bar curvature; i.e., to measure the average strain on the whole bar section. However, the gauges of the compressed reinforcements were arranged on the concave side of the bar if the deformed shape of the bar before buckling is considered. The aim of this arrangement was to detect buckling. In a displacement control test, in which deflections always increased, the reinforcement strain in the plastic hinge zone always increased. Nonetheless, when reinforcement buckled according to this compressed gauges arrangement, the strain recorded by gauges reduced, or tension strains were even recorded. Therefore onset of buckling is detected when compressed bar changes its curvature and, consequently, most compressed fibres of the cross section of the bar diminishes its compression strain level. A detailed description of this methodology to detect buckling of the compressed bar is depicted in Pereiro-Barceló and Bonet [1]. The gauges placed in transverse reinforcements were arranged every two consecutive stirrups.

In addition, a photogrammetric system was used to correct the distortion in the strains measured by the gauges due to the local curvature effect. The corrected strains of the compressed bar were obtained from both the strain of the tensioned bar and the position of the neuter fibre obtained by the photogrammetric analysis.
Five linear voltage displacement transductors (LVDTs) were placed at $0,325,675,1025$ and $1350 \mathrm{~mm}$ from the lower specimen edge to obtain the deformed shape in every instant. Moreover, thermocouples were placed on SMA bars to control the temperature changes attributed to the transformation phase.

\subsection{Experimental results and discussion}

\subsubsection{General results: load capacity, ductility, cracking patterns}

Fig. 4 shows the results of the VHPC columns with steel reinforcements. On the left of this figure, the normalised vertical load is shown $\left(v=N /\left(A_{c} f_{c m}\right)\right.$, where $N$ is the load applied by the hydraulic actuator, $A_{c}$ is the gross area of the section and $f_{c m}$ is the average strength under compression, depending on the longitudinal reinforcement strain $\varepsilon_{l}$, which is measured directly from strain gauges in the zone where compressed bar instability took place. The graphs are grouped according to fibre type, mixed (DRAMIX 13/0.16 and DRAMIX 80/30 BP) or long (DRAMIX 80/30 BP), and according to geometric cover ( 1 or $2 \mathrm{~cm}$ ). On the right of the same figure, normalised vertical load $(v)$ - normalised displacement $\left(\Delta / L_{\text {tot }}\right)$ is displayed, where $\Delta$ is the displacement at the midspan and $L_{\text {tot }}$ is the distance between load hinges. The onset of buckling is marked.

As all the VHPC specimens had the same fibre content, strength capacity was approximately similar in all cases. Differences appeared due to the distinct reinforcement batches (Table 3), the dispersion of tests and the dispersion in material properties (random orientation of fibres). No increase in strength capacity was observed because of the reduction in stirrups separation since effective transverse reinforcement confinement reduced when concrete strength rose. In relation to the post-peak branch slope, generally the following applied: the less separation of stirrups, the lower the absolute slope value. When comparing the results of the post-peak branch for a peak load fall of $20 \%$, no different results were observed with type of steel fibres (mixed (DRAMIX 13/0.16 and DRAMIX 80/30 BP) or long (DRAMIX 80/30 BP)) or cover thickness. However, regarding large displacements, the supported load in the columns made only with long fibres (VHPCLs...) was bigger than in the columns made with mixed fibres (VHPC-Ms...). This behaviour was because one wide crack was formed when a plastic hinge was generated and short fibres (DRAMIX 13/0.16) proved inefficient.

Fig. 5 shows the results of the specimens with SMA bars. The longitudinal strains $\varepsilon_{l}$ of specimen SMA-VHPC-Ls10T2 are not presented because of gauge failure. Load capacity was similar in all cases. The dispersion in concrete strengths caused slight differences. As the post-peak branch slope was similar in all cases, concrete type did not influence it. This fact was also observed in the steel specimens, as previously mentioned.

Fig. 6 compares the results $v-\Delta / L_{\text {tot }}$ of specimens VHPCMs10T2 and SMA-VHPC-Ls10T2. The initial stiffness of the column with the Ni-Ti compressed bars was lower than the columns with steel reinforcements. This behaviour happens because the $\mathrm{Ni}-\mathrm{Ti}$ austenitic modulus $\left(E_{A}=66647 \mathrm{MPa}\right)$ was 3 times inferior than the elastic modulus of the steel bar $\left(E_{s}=197.993 \mathrm{MPa}\right)$. The ductility of both types of elements was similar. The maximum load of column VHPC-Ms10T2 was greater than SMA-VHPC-Ls10T2 since the tensioned reinforcements of both specimens belonged to different batches. The batch allocated to specimen VHPC-Ms10T2 had a higher yield stress.

Fig. 7 displays the cracking patterns of the specimens. In the specimens made of VHPC and steel reinforcements, cracking under tension in the service state was well distributed due to both the high fibre content and the adherence that high strength concrete confers to fibres. Nevertheless in the failure state when the plastic 

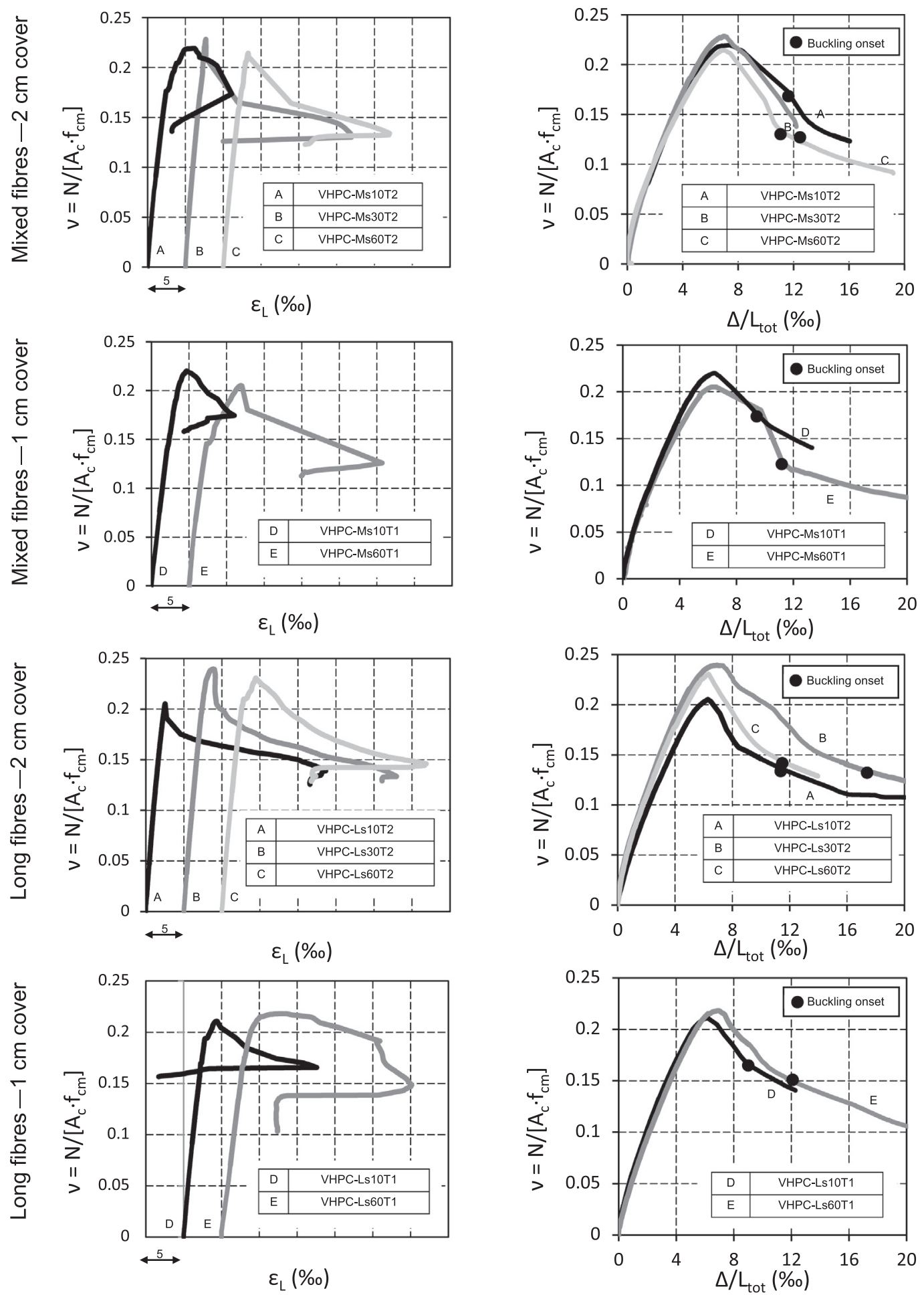

(a)

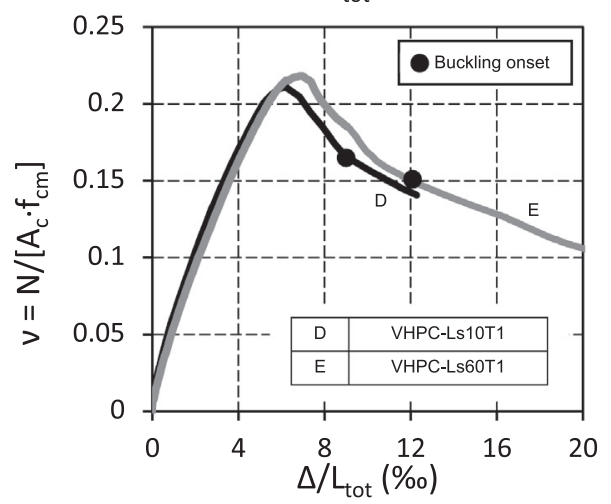

(b)

Fig. 4. Experimental results of the VHPC specimens with steel reinforcements: (a) Normalised load - axial strain $\left(v-\varepsilon_{l}\right)$, (b) Normalised load - normalised midspan displacement $\left(v-\Delta / L_{t o t}\right)$

hinge was formed, only one wide crack was formed (see Fig. 7). This crack emerged at the height of a stirrup because this zone represented a weak point for the concrete cover. Due to the good adherence of reinforcements with VHPC, the lengthening of reinforcements was enclosed in the wide crack width. As reinforcements were unable to redistribute lengthening in more length, high strains were recorded in the tensioned reinforcements. Even the tensioned reinforcements broke in two specimens due to this phenomenon (these two specimens are not included in this article because reinforcements broke before buckling occurred). The compressed zone cracking was longitudinal, well distributed and was noted shortly before the plastic hinge was generated. No differences in cracking patterns were observed between the specimens made of VHPC with mixed fibres (DRAMIX 13/0.16 and DRAMIX 

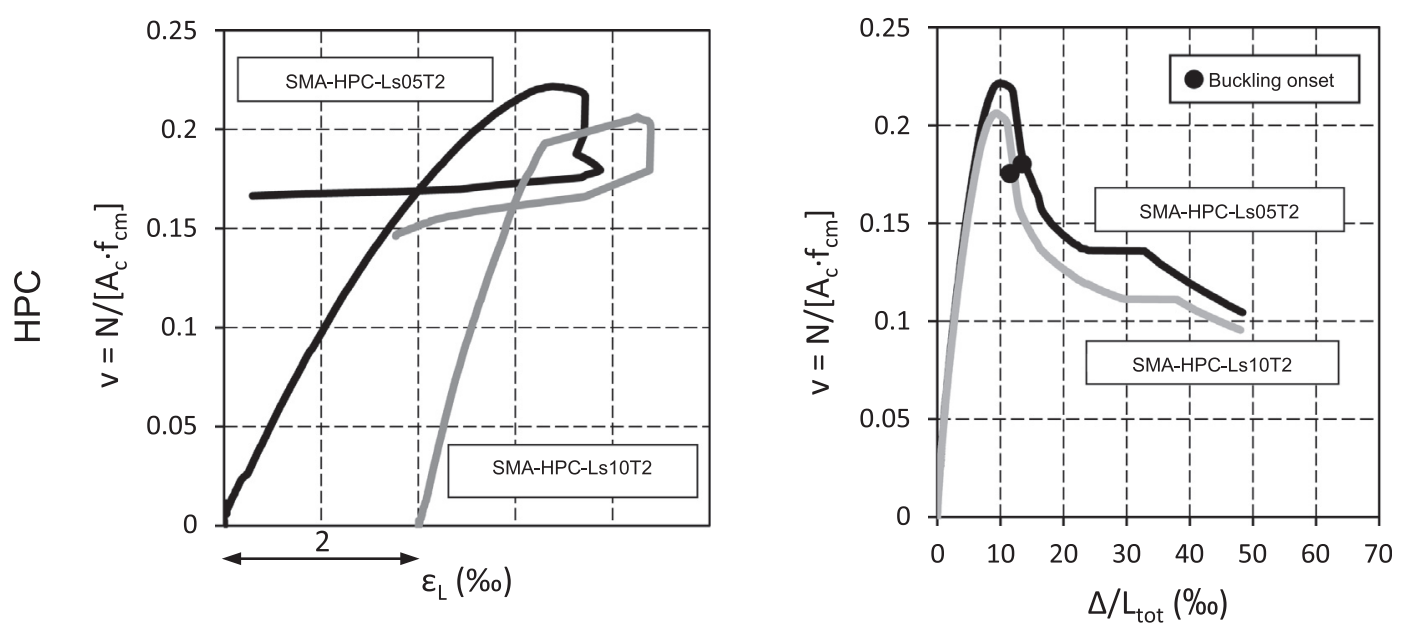

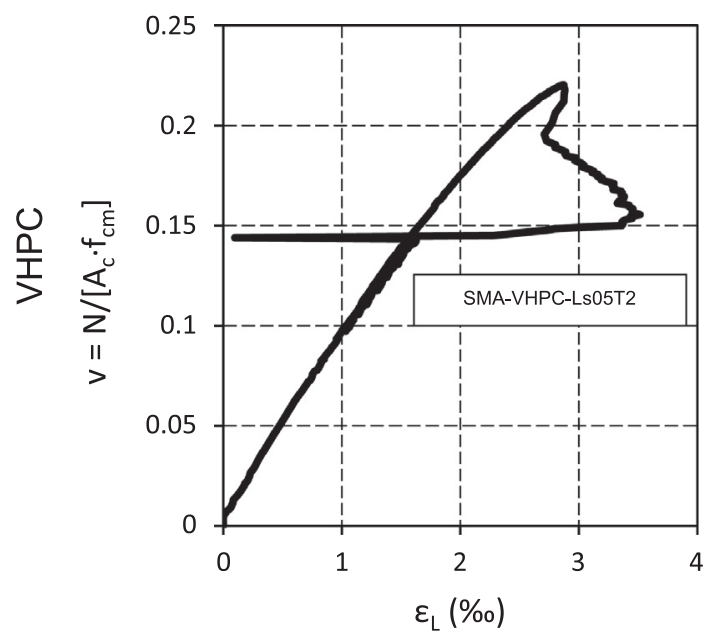

(a)

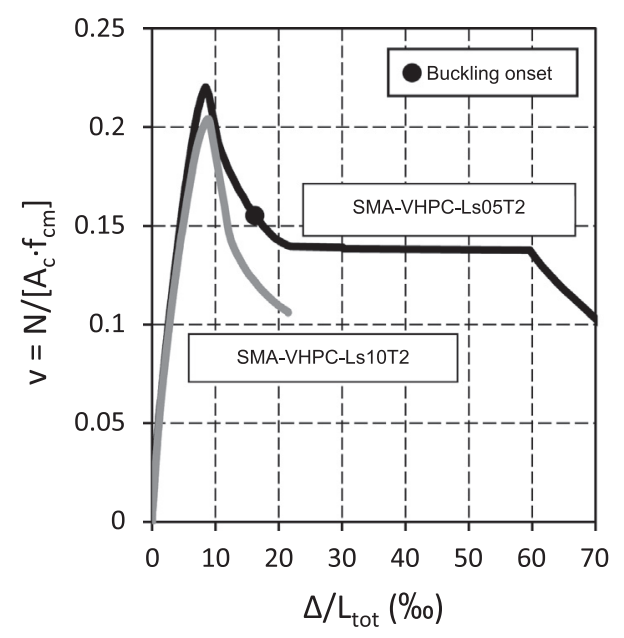

(b)

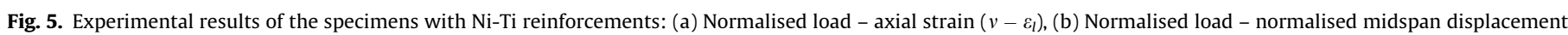
$\left(v-\Delta / L_{t o t}\right)$

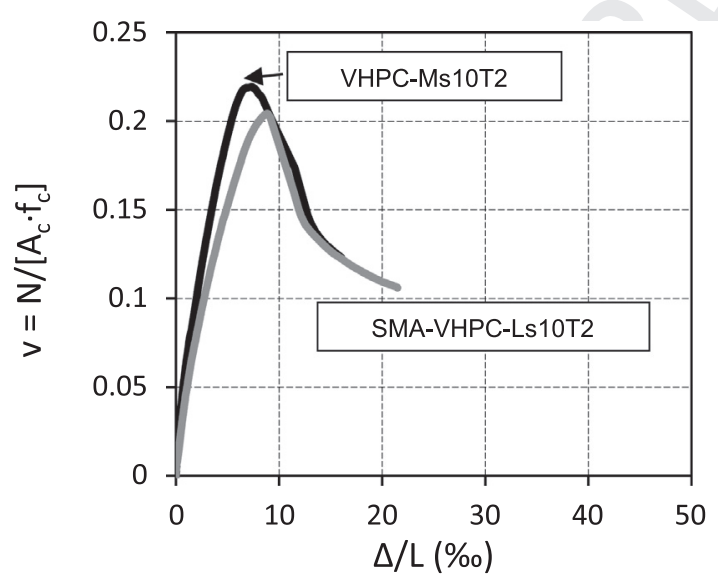

Fig. 6. Comparison between the VHPC elements with either steel or $\mathrm{Ni}-\mathrm{Ti}$ reinforcements.

80/30 BP) and those made only of long fibres (DRAMIX 80/30 BP). The cracking pattern of the specimens with Ni-Ti reinforcements and VHPC was similar to the specimens with steel reinforcements and VHPC. In the specimens with Ni-Ti reinforcements and HPC, the cracking morphology under both tension and compression was similar to the VHPC specimens, but less distributed.
Table 4 shows the experimental results about the maximum load situation and the instability situation of compressed bars. In this table the maximum load situation results are provided: applied axial load $N_{\text {máx }}[k N]$ and its corresponding horizontal displacement at midspan $\Delta[\mathrm{mm}]$. For the instability situation of compressed bars we see: applied axial load $N_{c}[\mathrm{kN}]$, its corresponding horizontal displacement at midspan $\Delta_{c}[\mathrm{~mm}]$, compressed bar strain $\varepsilon_{\text {crit }}$ ) and critical stress $\sigma_{\text {crit }}[\mathrm{MPa}]$. Once bar critical strain $\varepsilon_{\text {crit }}$ and the constitutive relations under compression of the compressed bar (Table 3) were known, the critical stress of the compressed bar was calculated, $\sigma_{\text {crit }}[\mathrm{MPa}]$. The two last columns in Table 4 are the result of applying the simplified expressions of the mixed model, which are explained in Sections 3 and 4.

\subsubsection{The buckling of reinforcements results}

This section explains the results that correspond to the buckling situation of bars. These results are grouped into three series: 1) VHPC columns and steel compressed reinforcements; 2) HPC columns and Ni-Ti compressed reinforcements; 3) VHPC columns and compressed $\mathrm{Ni}$-Ti reinforcements.

2.5.2.1. Columns made of VHPC and steel compressed bars. In this series, the fibres type, geometric cover thickness and tie spacing are analysed to determine their influence on the buckling of reinforcements. The fibres volume was always the same $\left(150 \mathrm{~kg} / \mathrm{m}^{3}\right)$, but 
(a)

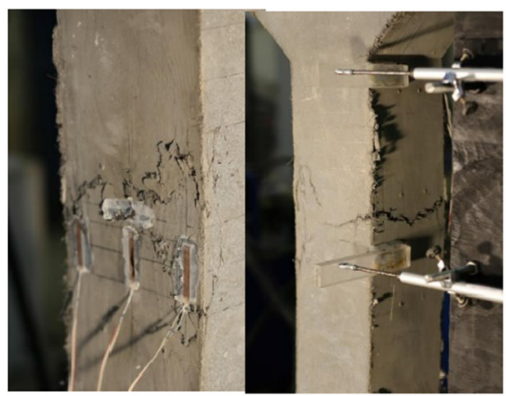

(c)

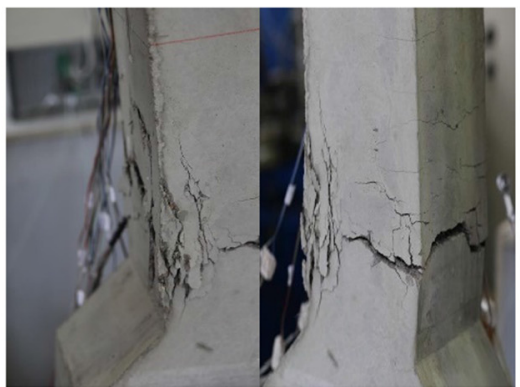

(e)

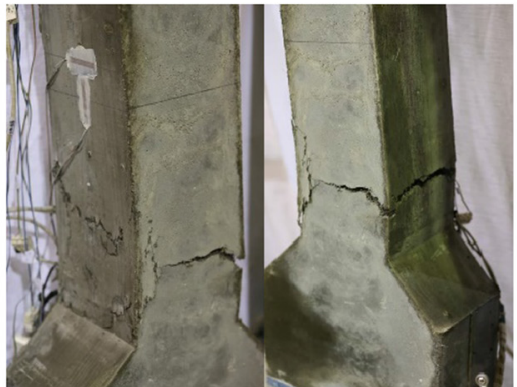

(b)

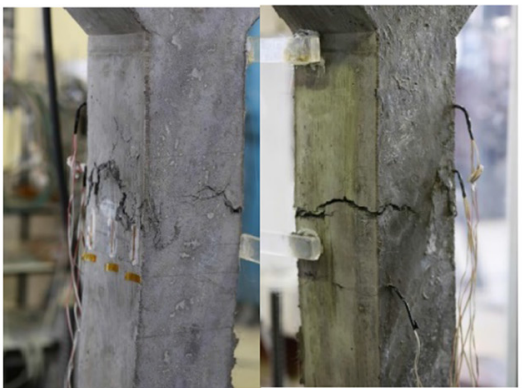

(d)

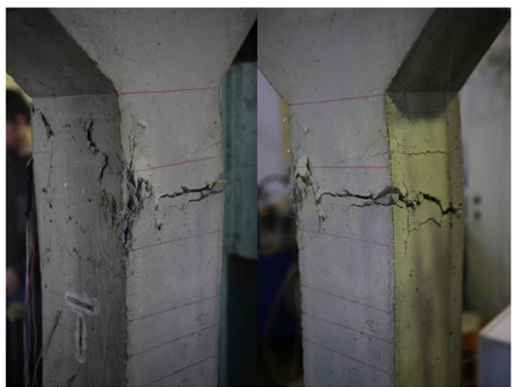

(f)

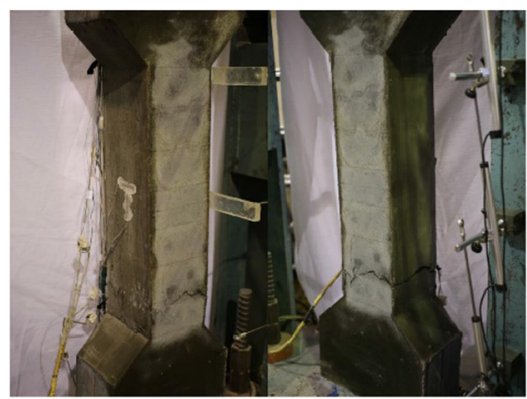

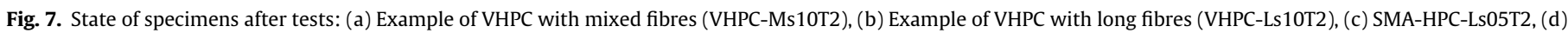
SMA-HPC-Ls10T2, (e) SMA-VHPC-Ls05T2, (f) SMA-VHPC-Ls10T2.

Table 4

Experimental campaign results and comparison with the proposed model.

\begin{tabular}{|c|c|c|c|c|c|c|c|c|}
\hline \multirow[t]{3}{*}{ Specimens } & \multicolumn{6}{|c|}{ Experimental results } & \multirow{2}{*}{\multicolumn{2}{|c|}{$\begin{array}{l}\text { Model results } \\
\text { Instability situation of compressed } \\
\text { bars }\end{array}$}} \\
\hline & \multicolumn{2}{|l|}{ Peak load } & \multicolumn{4}{|c|}{ Instability situation of compressed bars } & & \\
\hline & $\mathrm{N}_{\max }(\mathrm{kN})$ & $\Delta(\mathrm{mm})$ & $\mathrm{N}_{\mathrm{c}}(\mathrm{kN})$ & $\Delta_{\mathrm{c}}(\mathrm{mm})$ & $\varepsilon_{\text {crit }}(\% o)$ & $\sigma_{\text {crit }}(\mathrm{MPa})$ & $\varepsilon_{\text {crit,model }}(\%)$ & $\sigma_{\text {crit,model }}(\mathrm{MPa})$ \\
\hline VHPC-Ms10T2 & 1083.50 & 10.19 & 857.38 & 16.02 & 9.45 & 556.59 & 18.85 & 568.09 \\
\hline VHPC-Ms30T2 & 1127.33 & 9.66 & 612.44 & 24.40 & 17.30 & 566.19 & 20.05 & 569.56 \\
\hline VHPC-Ms60T2 & 1083.99 & 9.33 & 678.10 & 14.95 & 19.00 & 584.40 & 17.15 & 582.01 \\
\hline VHPC-Ms10T & 1091.76 & 8.98 & 866.08 & 13.28 & 10.03 & 557.30 & 15.63 & 564.15 \\
\hline VHPC-Ms60T1 & 1075.64 & 8.96 & 660.63 & 15.56 & 23.16 & 591.56 & 17.61 & 582.61 \\
\hline VHPC-Ls10T2 & 968.01 & 8.75 & 655.36 & 15.31 & 18.55 & 608.24 & 17.45 & 597.92 \\
\hline VHPC-Ls30T2 & 1100.18 & 9.65 & 612.44 & 24.40 & 22.33 & 575.55 & 19.6 & 569.01 \\
\hline VHPC-Ls60T2 & 1043.57 & 8.82 & 659.95 & 15.52 & 21.00 & 586.97 & 18.33 & 583.53 \\
\hline VHPC-Ls10T1 & 1061.97 & 8.58 & 834.01 & 12.65 & 16.11 & 564.74 & 19.50 & 568.88 \\
\hline VHPC-Ls60T & 915.59 & 9.65 & 623.54 & 17.09 & 22.87 & 627.77 & 14.25 & 593.48 \\
\hline SMA-HPC-Ls05T2 & 697.96 & 9.84 & - & - & 3.88 & 252.20 & $15.13 / 4.03$ & $503.19 / 262.12$ \\
\hline SMA-HPC-Ls10T2 & 692.07 & 9.36 & - & - & 2.40 & 156.00 & $14.75 / 2.57$ & $500.72 / 167.17$ \\
\hline SMA-VHPC-Ls05T2 & 944.15 & 8.48 & - & - & 3.51 & 228.15 & $15.90 / 4.03$ & $508.18 / 262.12$ \\
\hline SMA-VHPC-Ls10T2 & 942.59 & 8.85 & - & - & - & - & $17.66 / 2.57$ & $519.58 / 167.17$ \\
\hline
\end{tabular}

the typology of fibres changed: either only long fibres (DRAMIX $80 / 30 \mathrm{BP})$ or mixed ones $\left(90 \mathrm{~kg} / \mathrm{m}^{3}\right.$ of DRAMIX $13 / 0.16$ and 60 $\mathrm{kg} / \mathrm{m}^{3}$ of DRAMIX 80/30 BP). In all cases, the reinforcement buckled between stirrups ( $\eta \leqslant 1$, where $\eta=s / L, s$ is stirrups separation and $L$ is the length of the region involved in instability) according to the observations and, consequently, the concrete cover delayed buck- ling. In general, greater flexural strength $f_{R, 1}$ allowed a larger critical strain. As Table 4 shows, critical buckling strain $\varepsilon_{\text {crit }}$ was around 20\%, except for columns VHPC-Ms10T2 and VHPCMs10T1. Flexural strength $f_{R, 1}$ was around $20 \mathrm{MPa}$ in all specimens, except in column VHPC-Ls60T1, whose strength $f_{R, 1}$ was approximately $12 \mathrm{MPa}$. The anomaly in columns VHPC-Ms10T2 and 
VHPC-Ms10T1 happened because, despite obtaining a similar strength $f_{R, 1}$ to the other specimens, a lower critical strain was recorded. Although strength $f_{R, 1}$ in column VHPC-Ls60T1 was lower than the rest, the critical strain was similar to the rest, which also implied an anomalous result. These anomalies was explained by the dispersion of both specimen results and three-point flexural test because of the different orientation of fibres. In conclusion, the critical strain for the studied separations did not depend on the tie spacing since the longitudinal reinforcement buckled between stirrups. Neither did the fibres type nor the concrete cover thickness for the analysed ranges modify the critical strain.

Even though the columns with the $5-\mathrm{cm}$ tie spacing were not tested, the stirrups would be yielded due to the core dilatation for the critical strain that specimens reached (around 20\%). The strain of the longitudinal bars at which stirrups connected to them yield is between 6 and 10\%o [53]. In the VHPC elements, the strain at which the concrete cover was ineffective at delaying local buckling was higher than the longitudinal strain at which stirrups were yielded and, therefore, stirrups stiffness was neglected. Consequently, only the concrete cover delayed reinforcement buckling. If the aim was to achieve a strain beyond $20 \%$ without reinforcement buckling, the flexural properties of concrete should improve since an increased amount of transverse reinforcement would be inefficient because it would be yielded.

2.5.2.2. Columns made of HPC and compressed Ni-Ti bars. Ni-Ti bars had a polished surface. The research carried out by Mo and Chan [54] and that of Verderame et al. [55] demonstrated that the adherence of such bars reduced by $>70 \%$. This loss of adherence with concrete invalided the hypothesis of strain compatibility between $\mathrm{Ni}$-Ti bars and concrete [56], which was why the critical strains of $\mathrm{Ni}$-Ti bars were very low (Table 4 ). In all cases, Ni-Ti bars did not reach the strain of the onset of martensitic transformation. When a plastic hinge was formed, $\mathrm{Ni}$-Ti bar strain increased slightly due to the slight adherence with concrete. In these cases, stirrups were yielded when buckling occurred according to the gauges placed on stirrups. Consequently, stirrups stiffness was their plastic axial stiffness, which was low, but not null [49]. Therefore, the concrete cover was almost that which contained buckling until it was degraded.

2.5.2.3. Columns made of VHPC and Ni-Ti compressed bars. As with HPC with Ni-Ti specimens, very little adherence existed between $\mathrm{Ni}-\mathrm{Ti}$ and concrete. For this reason, once again the critical strain that the gauges recorded in $\mathrm{Ni}-\mathrm{Ti}$ bars was very low compared to the specimens with steel bars. Stirrups were yielded when the bar buckled according to the gauges located at the stirrups.

\section{Summary of simplified expressions to determinate critical buckling stress}

The mixed model proposed by Pereiro-Barceló and Bonet [3] provides simplified expressions to determine the critical buckling stress of compressed reinforcements $\sigma_{\text {crit }}$ in plain or fibrereinforced concrete elements. Stress $\sigma_{\text {crit }}$ depends on the stiffness of the transverse and longitudinal reinforcement, on the distributed stiffness of the concrete cover, and also on tie spacing $s$. Longitudinal reinforcement stiffness is $E_{r} I$, where $I$ is the inertia moment and $E_{r}$ is the reduced modulus of longitudinal reinforcement [57]. This modulus is replaced with elasticity modulus $E_{s}$ when buckling is produced at a strain lower than the yield strain.

Transverse reinforcement is modelled as discrete tensioned springs with stiffness $\alpha_{s}$, whereas the concrete cover is modelled continuously along the instability length with stiffness $\alpha_{c}$. Pereiro-Barceló and Bonet [3] experimentally calibrated a value of $\alpha_{c}=70 \mathrm{MPa}$ for NSC with fibres. They also experimentally calibrated the longitudinal reinforcement strain $\left(\varepsilon_{c r i t, \eta \leqslant 1}\right.$, Expression (3)) that was dependent on $f_{R, 1}$ from which the proposed value of $\alpha_{c}$ could not be guaranteed because of concrete degradation.

$\varepsilon_{c r i t, \eta \leqslant 1}=0.66 \cdot f_{R, 1}+7.15\left(f_{R, 1}\right.$ in MPa and $\varepsilon_{c r i t, \eta \leqslant 1}$ in $\left.\%\right)$

The critical buckling stress of the compressed reinforcements is determined by means Expression (4).

$\sigma_{\text {crit }}=c_{c} \frac{\pi^{2} E_{r} I}{s^{2} A}$

where:

$s$ : Tie spacing

$E_{r}$ : The reduced modulus of the longitudinal reinforcement proposed by Papia et al. [57]

I: The inertia moment of longitudinal reinforcement

$A$ : The transverse reinforcement area

$c_{c}$ : The critical adimensional stress (Table 5 ). $c_{c}$ is the relation between the critical buckling stress of the bar and the critical buckling stress of the bar hinged between two consecutive rigid stirrups $\left(\frac{\pi^{2} E_{r} I}{s^{2} A}\right) \cdot c_{c}$ depends on relation $\gamma$ (Expression (5)) between transverse reinforcement axial stiffness $\alpha_{s}$ and the bending stiffness of longitudinal bar $E_{r} I$. Besides, $c_{c}$ depends on the relation $k_{c s}$ (Expression (6)) between concrete cover axial stiffness $\alpha_{c}$ and transverse reinforcement axial stiffness $\alpha_{s}$

$\gamma=\alpha_{s} s^{3} E_{r} I$

$k_{c s}=\frac{\alpha_{c}}{\alpha_{s}} s$

Expression (7) shows transverse reinforcement stiffness $\alpha_{s}$.

$\alpha_{s}=\frac{E_{s w} \cdot A_{s w}}{L_{e f}}$

where

$E_{s w}$ : The tangent modulus of transverse reinforcement. In order to know this modulus, it is necessary to determine if reinforcement is yielded or not. For this purpose, it is necessary to relate the transverse strain to the longitudinal strain through the dilatancy parameter [53,58-60].

$A_{s w}$ : The transverse reinforcement area.

$L_{e f}$ : The effective transverse reinforcement length, which depends on the reinforcement arrangement and type of load (concentric or eccentric) (Pereiro-Barceló and Bonet [3]).

Table 5

Simplified expressions from the mixed model proposed by Pereiro-Barceló and Bonet [3] to determine critical adimensional stress.

\begin{tabular}{|c|c|c|}
\hline$k_{c s}=0$ & $c_{c}=4 \cdot\left(1-\frac{1}{1+0.09 \gamma^{0.58}}\right)$ & \\
\hline \multirow[t]{10}{*}{$0<k_{c s} \leqslant 30$} & $\begin{array}{l}c_{c}=a_{1} * e^{b_{1} \cdot \log _{10} \gamma}+c_{1} \\
\text { where: }\end{array}$ & if $c_{c} \geqslant c_{c_{\eta=1.4}}(\gamma)$ \\
\hline & $a_{1}=0.35 k_{c s}^{0.5}-0.0066$ & \\
\hline & $b_{1}=\frac{1.15 k_{c s}+0.035}{k_{c s}+0.029}$ & \\
\hline & $c_{1}=\frac{-0.0116 k_{c s}+0.062}{k_{c s}+0.036}$ & \\
\hline & $\gamma=\alpha_{s} s^{3} / E_{r} I$ & \\
\hline & $c_{c_{\eta=1.4}}(\gamma)=-0.00124\left(\log _{10} \gamma\right)^{7}+4.8$ & \\
\hline & $\begin{array}{l}c_{c}=a_{2} * e^{b_{2} \cdot \log _{10} \gamma}+c_{2} \\
\text { where: }\end{array}$ & if $c_{c}<c_{c_{\eta}=1.4}(\gamma)$ \\
\hline & $a_{2}=\frac{5.5 k_{c s}^{3}+99.3 k_{c s}^{2}+189 k_{c s}+91.2}{k_{c s}^{3}+93 k_{c s}^{2}+417 k_{c s}+25.4}$ & \\
\hline & $b_{2}=\frac{1.14 k_{\mathrm{cs}}^{2}+1.26 k_{\mathrm{cs}}+0.08}{k_{\mathrm{sc}}^{2}+1.535 k_{\mathrm{cs}}+0.404}$ & \\
\hline & $c_{2}=\frac{-0.02 k_{c s}^{2}-0.375 k_{c s}-1.07}{k_{c s}^{2}+5 k_{c s}+0.325}$ & \\
\hline$k_{c s}>30$ & $c_{c}=\left(\frac{s}{\pi}\right)^{2} \sqrt{\frac{12 \alpha_{c}}{E_{r} I}}$ & \\
\hline
\end{tabular}




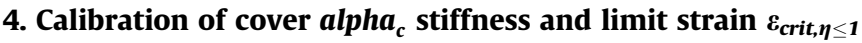

In this section stiffness $\alpha_{c}$ and strain $\varepsilon_{c r i t, \eta \leqslant 1}$ until $\alpha_{c}$ was guaranteed (Expression (3)) were recalibrated based on the experimental results (Section 2) in order to consider VHPC elements. To achieve this, the simplified expressions of the mixed model (Section 3 ) were used. In this case, critical buckling stress $\sigma_{\text {crit }}$ was known through the experimental results and stiffness $\alpha_{c}$ was the parameter to recalibrate using the model. The VHPC elements with steel reinforcements were used for recalibration purposes. The specimens used were those in which transverse reinforcement did not intervene in delaying buckling $(\eta \leqslant 1)$, i.e., those in which the reinforcement buckled between stirrups. This happened in all the VHPC specimens with steel reinforcements. Consequently, all these specimens were used, except for those that showed anomalous results (VHPC-Ms10T2, VHPC-Ms10T1 and VHPC-Ls60T1). The specimens with Ni-Ti bars were not used in this analysis since adherence with concrete failed. As transverse reinforcements did not intervene, then $\alpha_{s}=0$ and, as a result, $k_{c s}>30$. Therefore, concrete cover stiffness $\alpha_{c}$ (Expression (8)) was obtained by replacing the critical adimensional stress for $k_{c s}>30$ (Table 5) in Expression (4):

$\alpha_{c}=\frac{\pi \sigma_{c r i t}^{2}}{3 E_{r}}$

Fig. 8 shows the results of $\alpha_{c}$ that is dependent on $f_{R, 1}$. This figure also represents the results of the NSFRC specimens according to Pereiro-Barceló and Bonet [3] and those HPC ones tested by Pereiro-Barceló [61]. Pereiro-Barceló and Bonet [3] affirmed that $\alpha_{c}$ had an independent value of $f_{R, 1}$ and had a value of $70 \mathrm{MPa}$ for NSFRC. However, the addition of the HPC and VHPC results evidenced that $\alpha_{c}$ maintained a linear relation with $f_{R, 1}$. The linear equation that linked $\alpha_{c}$ with $f_{R, 1}$ is displayed in Expression (9).

$\alpha_{c}=0.23 f_{R, 1}+67.6\left(\alpha_{c}\right.$ and $f_{R, 1}$ in $\left.M P a\right)$

As there were different steel qualities ( 3 batches with yield stresses of 545,560 and $575 \mathrm{MPa}$ ), different critical stresses $\sigma_{\text {crit }}$ should have been obtained depending on the steel batch (with all the other parameters equal) and, consequently, should have different values of $\alpha_{c}$ (8). Nevertheless, these differences were not noted due to both the inherent dispersion of the results in such experimental tests, and there were few differences in yield stresses.

Concrete cover stiffness $\alpha_{c}$ reduced at the same time that the longitudinal reinforcement strain increased. However, only one experimental point of this relationship was determined $\left(\alpha_{c}\right.$, $\varepsilon_{\text {crit }, \eta \leqslant 1}$ ). For this reason, stiffness $\alpha_{c}$ in Expression (9) was not guaranteed beyond strain $\varepsilon_{\text {crit }, \eta \leqslant 1}$.

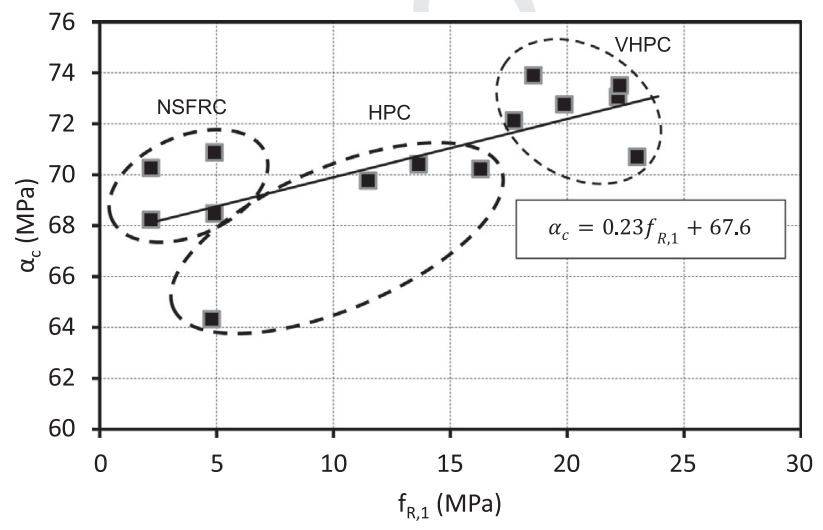

Fig. 8. Concrete cover stiffness $\alpha_{c}$-residual tensile strength $f_{R, 1}$.
Fig. 9 displays the relationship between strain $\varepsilon_{c r i t, \eta \leqslant 1}$ and $f_{R, 1}$. Expression (10) shows the equation of $\varepsilon_{c r i t, \eta \leqslant 1}$, where $\varepsilon_{c r i t, \eta \leqslant 1}$ is expressed in $\%$ and $f_{R, 1}$ in MPa. The expression continues to be a straight line, so linear behaviour did not change when the VHPC and HPC [61] elements were incorporated.

$\varepsilon_{\text {crit }, \eta \leqslant 1}=0.55 f_{R, 1}+7.4$

Table 4 shows the results of the critical stress and strain obtained by applying the simplified expressions of the mixed model (Section 3) with the recalibrated values of $\alpha_{c}$ and $\varepsilon_{c r i t . \eta \leqslant 1}$ shown in Expressions (9) and (10). Determination coefficient $R^{2}$ between the experimental and numerical, after results discounting the three anomalous specimens, was 0.896 for strains and 0.998 for stresses. The dilatancy criterion used to know the transverse strain and, therefore, if stirrups were yielded, was that proposed by Lokuge et al. [53]. In order to obtain the buckling strain and stress in steel reinforcements, the strain of the bar was progressively increased until the buckling stress equaled the steel stress obtained from its fundamental constitutive curve. Reduced modulus $E_{r}$ [57] depended on both elastic modulus $E_{s}$ and the tangent modulus at buckling point $E_{h}$. The buckling strain was always lower than the strain at which the steel entered the hardening branch $\left(\varepsilon_{s h}\right)$ in all the tested specimens. Therefore, the tangent modulus at buckling point $E_{h}$ coincided with the plastic modulus of steel.

It is necessary to point out that, with other reinforcements not made from steel, expression $\alpha_{c}$ (9) and strain expression $\varepsilon_{c r i t, \eta \leqslant 1}$ (10) can be used because they are inherent parameters to the concrete cover.

For the columns made with $\mathrm{Ni}$-Ti bars, since the adherence between bars and VHPC did not exist, two pairs of critical stresses and critical strain values are provided in Table 4. The first value is that associated with the critical situation when considering perfect adherence between $\mathrm{Ni}$-Ti bars and concrete. Therefore, the simplified expressions of the mixed model (Section 3 ), recalibrated with values $\alpha_{c}$ and $\varepsilon_{c r i t, \eta \leqslant 1}$ of Section 4, were used and the same procedure as for the steel was followed. The second value was obtained by considering no adherence between the bar and concrete. In order to calculate it, the cover was assumed to not exist and stirrups were yielded. The onset of the strains of the Ni-Ti bar was considered to be $\varepsilon_{c r i t, \eta \leqslant 1}$; i.e., when the concrete cover is not efficient. As mentioned in Section 2.5.2, when the concrete cover reached strain $\varepsilon_{c r i t, \eta \leqslant 1}$, transverse reinforcements were yielded. Therefore, $\alpha_{c}=0$ and $\alpha_{s}=\alpha_{s, y} \neq 0$ (stirrups had no null stiffness on the plastic branch (Table 3)) were considered to calculate critical stress and

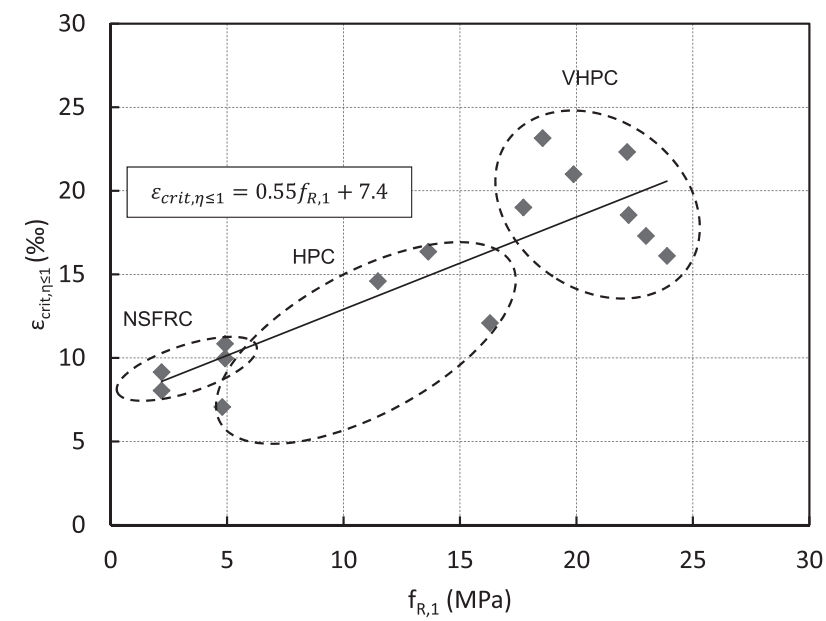

Fig. 9. Compressed bar strain in the instability situation $\left(\varepsilon_{c r i t, \eta \leqslant 1}\right)$ - residual tensile strength $f_{R, 1}$. 
strain when the adherence between $\mathrm{Ni}$-Ti bars and concrete was not taken into account.

\section{Summary and conclusions}

An experimental campaign was carried out with 10 VHPC columns and steel reinforcements, two VHPC columns with $\mathrm{Ni}-\mathrm{Ti}$ reinforcements and 2 HPC columns with Ni-Ti reinforcements. The local buckling of the compressed reinforcements was experimentally assessed in them all. With the experimental results, the model to determine the buckling critical stress of Pereiro-Barceló and Bonet [3] was extended. This model considered elements made of FRNSC and was extended to take into account HPC and VHPC elements.

The conclusions drawn from the experimental campaign are as follows:

- Longitudinal reinforcement buckling occurred between the stirrups in all the specimens made of VHPC and steel reinforcements. Only the concrete cover was able to prevent the compressed bar from buckling. The critical buckling strain of the compressed bars increased as both the fibres content augmented and concrete strength improved.

- The cracking under tension in the service state and the cracking under compression were distributed in the VHPC specimens. Under tension with service loads, the first visible cracks began at the stirrups height; with ultimate loads, a single wide crack was formed. For large crack openings, the specimens made of VHPC with long fibres $(30 \mathrm{~mm})$ were more ductile than those fabricated with mixed fibres (fibres of $30 \mathrm{~mm}$ and $13 \mathrm{~mm}$ ).

- The cracking pattern of the VHPC specimens with Ni-Ti reinforcements was similar to the same specimens with steel reinforcements. In the specimens with $\mathrm{Ni}-\mathrm{Ti}$ and $\mathrm{HPC}$ reinforcements, the cracking morphology under both tension and compression was similar to the specimens made of VHPC, but less distributed. The concrete degradation of the fibreconcrete cover of the VHPC specimens was lesser than for the HPC specimens.

- The VHPC specimens cover became less efficient to delay local the buckling of reinforcements for strains of around $20 \%$. For this level of strains, stirrups were yielded due to core dilatation. Consequently, once the cover was inefficient, the compressed bar buckled regardless of stirrups separation.

- In the columns with Ni-Ti bars, no adherence between the polished bars and concrete existed. For the concretes with a high fibre content, the concrete cover was responsible for preventing bars from buckling. When it was inefficient, stirrups were yielded and, consequently, the Ni-Ti bar buckling stress corresponded to the critical stress of an isolated bar with yielded stirrups. The fact that $\mathrm{Ni}-\mathrm{Ti}$ had an austenitic modulus that was 3 times inferior to the steel elasticity modulus meant that this type of material buckled more easily from the time at which the concrete cover became inefficient. For this reason, using a concrete with a high fibre content delays the buckling of $\mathrm{Ni}-\mathrm{Ti}$ bars. Using Ni-Ti bars in concretes without fibres would prove inefficient.

- In the specimens with Ni-Ti bars, the supports made of VHPC were more ductile than the HPC ones. The higher the fibres content, the greater ductility becomes. From the strength point of view, strength capacity increased as the compressive strength of concrete rose. The effect of tie spacing (effective confinement) reduced when strength increased.

- The less austenitic modulus of Ni-Ti bars compared to the elasticity modulus of steel bars meant a reduction in the initial stiffness of columns.
Fibre-concrete cover stiffness $\alpha_{c}$ and strain $\varepsilon_{c r i t, \eta \leqslant 1}$ were calibrated to consider the NSC, FRNSC, HSC, FRHSC (or HPC) and VHPC elements. For both parameters, an increasing linear relationship with flexural strength $f_{R, 1}$ was established.

According to the experimental results, the calibrated simplified expressions used to determine the local buckling critical strains and stresses showed adequate precision.

\section{Acknowledgements}

The research presented herein forms part of a research undertaken at the Concrete Science and Technology Institute (ICITECH) of the Universitat Politècnica de València (UPV). The authors are sincerely grateful to the Spanish Ministry of Economy and Competitiveness for the help provided through Project BIA2012-32645, and to the European Union for the financial support obtained from FEDER funds. The authors wish to thank the Spanish Ministry of Education, Culture and Sport for Grant FPU12/01451.

\section{References}

[1] M.M. Kashani, A.K. Barmi, V.S. Malinova, Influence of inelastic buckling on lowcycle fatigue degradation of reinforcing bars, Constr. Build. Mater. 94 (2015) 644-655, https://doi.org/10.1016/j.conbuildmat.2015.07.102.

[2] Y.-L. Bai, J.-G. Dai, J.G. Teng, Buckling of steel reinforcing bars in FRP-confined RC columns: an experimental study, Constr. Build. Mater. 140 (2017) 403-415, https://doi.org/10.1016/j.conbuildmat.2017.02.149.

[3] J. Pereiro-Barceló, J.L. Bonet, Mixed model for the analytical determination of critical buckling load of passive reinforcement in compressed RC and FRC elements under monotonic loading, Eng. Struct. 150 (2017) 76-90, https://doi. org/10.1016/j.engstruct.2017.07.026.

[4] J. Pereiro-Barceló, J.L. Bonet, Ni-Ti SMA bars behaviour under compression, Constr. Build. Mater. 155C (2017) 348-362.

[5] Fomento EM de, Hormigón ECP del. EHE-08: Instrucción de Hormigón Estructural: con comentarios de los miembros de la Comisión Permanente del Hormigón, 2008.

[6] EN 1998-1; Eurocode 8: Design of structures for earthquake resistance - Part 1: General rules, seismic actions and rules for buildings, 2004.

[7] EN 1998-2; Eurocode 8: Design of concrete structures - Part 2: Bridges, 2005

[8] ACI Committee 318, ACI 318-14: Building Code Requirements for Structural Concrete and Commentary, 2014.

[9] R.P. Dhakal, Post-peak response analysis of SFRC columns including spalling and buckling, Struct. Eng. Mech. 22 (2006) 311-330.

[10] G. Campione, Compressive behavior of short fibrous reinforced concrete members with square cross-section, Struct. Eng. Mech. 37 (2011) 649-669.

[11] J.C. Walraven, High performance fiber reinforced concrete: progress in knowledge and design codes, Mater. Struct. 42 (2009) 1247-1260, https:// doi.org/10.1617/s11527-009-9538-3.

[12] A. Spasojevic, Structural implications of ultra-high performance fibrereinforced concrete in bridge design, 2008.

[13] E. Fehling, M. Schmidt, J. Walraven, T. Leutbecher, S. Fröhlich, Ultra-High Performance Concrete UHPC. Ultra-High Perform. Concr. UHPC, Wilhelm Ernst \& Sohn, Verlag für Architektur und technische Wissenschaften GmbH \& Co. KG, 2014, p. $183-8$.

[14] L. Hsu, C.T. Hsu, Stress-strain behavior of steel-fiber high-strength concrete under compression, ACI Struct. J. 91 (1994) 448-457.

[15] S.J. Foster, On behavior of high-strength concrete columns: cover spalling steel fibers, and ductility, ACI Struct. J. 98 (2001) 583-589.

[16] H. Aoude, W.D. Cook, D. Mitchell, Behavior of columns constructed with fibers and self-consolidating concrete, ACI Struct. J. 106 (2009) 349.

[17] G. Campione, M. Fossetti, M. Papia, Behavior of fiber-reinforced concrete columns under axially and eccentrically compressive loads, ACI Struct. J. 107 (2010) 272-281

[18] P. Paultre, R. Eid, Y. Langlois, Y. Lévesque, Behavior of Steel Fiber-Reinforced High-Strength Concrete Columns under Uniaxial Compression Read More: http://ascelibrary.org/doi/abs/10.1061/\%28ASCE\%29ST.1943-541X.0000211, ASCE 2010, 136.

[19] K.E. Caballero-Morrison, J.L. Bonet, J. Navarro-Gregori, J.R. Martí-Vargas, Behaviour of steel-fibre-reinforced normal-strength concrete slende columns under cyclic loading, Eng. Struct. 39 (2012) 162-175, https://doi. org/10.1016/j.engstruct.2012.02.003.

[20] Castro Bugallo M del C. Análisis experimental de soportes de hormigón de altas prestaciones sometidos a compresión y carga lateral cíclica. Tesis Doctoral. Universitat Politècnica de València, 2015.

[21] M.S. Saiidi, M. Tazarv, B. Nakashoji, S. Varela, F. Kavianipour, Resilient and sustainable bridges of the future, Int. J. Bridge. Eng. IJBE 3 (2015) 37-48.

[22] J.L. Bonet, J. Pereiro-Barceló, A. Navarro-Gómez, Smart Seismic Concrete Connection, 2016, P201631022, n.d. 
[23] J. Osteraas, H. Krawinkler, The Mexico Earthquake of September 19, 1985Behavior of Steel Buildings, Earthq Spectra 5 (1989) 51-88, https://doi.org/ $10.1193 / 1.1585511$

[24] H. Kim, S. Goel, Seismic Evaluation and Upgrading of Braced Frame Structures for Potential Local Failures. UMCEE 92-24, Dept. of Civil Engineering and Environmental EngineeringUniv. of Michigan, Ann Arbor, 1992.

[25] R. Tremblay, A. Filiatrault, P. Timler, M. Bruneau, Performance of steel structures during the 1994 Northridge earthquake, Can. J. Civ. Eng. 22 (1995) 338-360.

[26] R. DesRoches, J. McCormick, M. Delemont, Cyclic properties of superelastic shape memory alloy wires and bars, J. Struct. Eng. ASCE 130 (2004) 38-46.

[27] M. Branco, L. Guerreiro, K.K. Mahesh, F.M. Braz Fernandes, Effect of load cycling on the phase transformations in $\mathrm{Ni}-\mathrm{Ti}$ wires for civil engineering applications, Constr. Build. Mater. 36 (2012) 508-519, https://doi.org/10.1016/ j.conbuildmat.2012.06.003.

[28] A. Cladera, B. Weber, C. Leinenbach, C. Czaderski, M. Shahverdi, M. Motavalli, Iron-based shape memory alloys for civil engineering structures: an overview, Constr. Build. Mater. 63 (2014) 281-293, https://doi.org/10.1016/ j.conbuildmat.2014.04.032.

[29] H. Fang, M.B. Wong, Y. Bai, R. Luo, Effect of heating/cooling rates on the material properties of NiTi wires for civil structural applications, Constr Build

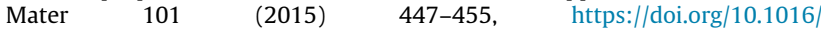
j.conbuildmat.2015.10.081.

[30] A.H.M. Muntasir Billah, Alam M. Shahria, Seismic performance of concrete columns reinforced with hybrid shape memory alloy (SMA) and fiber reinforced polymer (FRP) bars, Constr. Build. Mater. 28 (2012) 730-742, https://doi.org/10.1016/j.conbuildmat.2011.10.020.

[31] C. Qiu, S. Zhu, Characterization of cyclic properties of superelastic monocrystalline $\mathrm{Cu}-\mathrm{Al}-\mathrm{Be}$ SMA wires for seismic applications, Constr. Build.

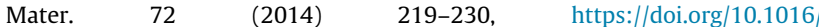
j.conbuildmat.2014.08.065.

[32] C. Czaderski, M. Shahverdi, R. Brönnimann, C. Leinenbach, M. Motavalli, Feasibility of iron-based shape memory alloy strips for prestressed strengthening of concrete structures, Constr. Build. Mater. 56 (2014) 94-105, https://doi.org/10.1016/j.conbuildmat.2014.01.069.

[33] Q. Chen, M. Shin, B. Andrawes, Experimental study of non-circular concrete elements actively confined with shape memory alloy wires, Constr. Build.

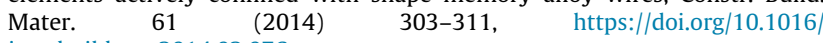
j.conbuildmat.2014.02.076.

[34] W.J. Lee, B. Weber, C. Leinenbach, Recovery stress formation in a restrained FeMn-Si-based shape memory alloy used for prestressing or mechanical joining. Constr. Build. Mater. 95 (2015) 600-610, https://doi.org/10.1016/ j.conbuildmat.2015.07.098.

[35] M.K. Kim, D.J. Kim, Y.-S. Chung, E. Choi, Direct tensile behavior of shapememory-alloy fiber-reinforced cement composites, Constr. Build. Mater. 102 (Part 1) (2016) 462-470, https://doi.org/10.1016/j.conbuildmat.2015.11.015.

[36] M. Shahverdi, C. Czaderski, M. Motavalli, Iron-based shape memory alloys for prestressed near-surface mounted strengthening of reinforced concrete beams, Constr. Build. Mater. 112 (2016) 28-38, https://doi.org/10.1016/ j.conbuildmat.2016.02.174.

[37] M.A. Rahman, J. Qiu, J. Tani, Buckling and postbuckling characteristics of the superelastic SMA columns, Int. J. Solids Struct. 38 (2001) 9253-9265.

[38] M.A. Rahman, J. Tani, Postbuckling characteristics of the short superelastic shape memory alloy columns-experiment and quantitative analysis, Appl. Mech. Eng. 11 (2006) 941.

[39] L. Hussein, L. Amleh, Structural behavior of ultra-high performance fiber reinforced concrete-normal strength concrete or high strength concrete composite members, Constr. Build. Mater. 93 (2015) 1105-1116, https://doi. org/10.1016/j.conbuildmat.2015.05.030.

[40] S. Xu, A. Li, Z. Ji, Y. Wang, Seismic performance of reinforced concrete columns after freeze-thaw cycles, Constr. Build. Mater. 102 (2016) 861-871, https:// doi.org/10.1016/j.conbuildmat.2015.10.168.
[41] M.A. Al-Osta, M.N. Isa, M.H. Baluch, M.K. Rahman, Flexural behavior of reinforced concrete beams strengthened with ultra-high performance fiber reinforced concrete, Constr. Build. Mater. 134 (2017) 279-296, https://doi.org/ 10.1016/j.conbuildmat.2016.12.094.

[42] M. Singh, A.H. Sheikh, M.S. Mohamed Ali, P. Visintin, M.C. Griffith, Experimental and numerical study of the flexural behaviour of ultra-high performance fibre reinforced concrete beams, Constr. Build. Mater. 138 (2017) 12-25, https://doi.org/10.1016/j.conbuildmat.2017.02.002.

[43] P. Hála, R. Sovják, M. Frydrýn, T. Mičunek, Energy absorbing system made of high performance concrete, Constr. Build. Mater. 139 (2017) 64-80, https:// doi.org/10.1016/j.conbuildmat.2017.02.048.

[44] D.-Y. Yoo, N. Banthia, Size-dependent impact resistance of ultra-highperformance fiber-reinforced concrete beams, Constr. Build. Mater. 142 (2017) 363-375, https://doi.org/10.1016/j.conbuildmat.2017.03.080.

[45] EN 1992-1-1; Eurocode 2: Design of concrete structures - Part 1-1: General rules and rules for buildings, 2004.

[46] Asociación española de normalización y certificación, AENOR. UNE-EN 123903.Ensayos de hormigón endurecido - Parte 3: Determinación de la resistencia a compresión de probetas, 2000.

[47] Asociación española de normalización y certificación, AENOR. UNE-EN 14651:2007, Método de ensayo para hormigón con fibras metálicas. Determinación de la resistencia a la tracción por flexión (límite de proporcionalidad (LOP), resistencia residual 2007

[48] AENOR, Spanish Association for Standards and Certification. UNE-EN 10002-1. Metallic materials. Tensile testing, Part 1: Method of test at ambient temperature, 2002

[49] L.L. Dodd, J.I. Restrepo-Posada, Model for predicting cyclic behavior of reinforcing steel, J. Struct. Eng. 121 (1995) 433-445.

[50] ASTM F2004 - 05, Standard Test Method for Transformation Temperature of Nickel-Titanium Alloys by Thermal Analysisoja.pdf, 2010.

[51] F. Auricchio, E. Sacco, A Superelastic Shape-Memory-Alloy Beam Model, J. Intell. Mater. Syst. Struct. 8 (1997) 489-501, https://doi.org/10.1177/ $1045389 \times 9700800602$.

[52] L. Orgéas, D. Favier, Non-symmetric tension-compression behaviour of NiTi alloy, J. Phys IV (1995). 05:C8-605-C8-610 10.1051/jp4/199558605.

[53] W.P. Lokuge, J.G. Sanjayan, S. Setunge, Stress-strain model for laterally confined concrete, J. Mater. Civ. Eng. 17 (2005) 607-616, https://doi.org/ 10.1061/(ASCE)0899-1561(2005) 17:6(607).

[54] Y.L. Mo, J. Chan, Bond and slip of plain rebars in concrete, J. Mater. Civ. Eng. 8 (1996) 208-211.

[55] G.M. Verderame, Carlo G De, P. Ricci, G. Fabbrocino, Cyclic bond behaviour of plain bars. Part II: analytical investigation, Constr. Build. Mater. 23 (2009) 3512-3522, https://doi.org/10.1016/j.conbuildmat.2009.07.001.

[56] M. Tazarv, Saiidi M. Saiid, Low-Damage precast columns for accelerated bridge construction in high seismic zones, J. Bridge Eng. 21 (2016) 04015056, https:// doi.org/10.1061/(ASCE)BE.1943-5592.0000806.

[57] M. Papia, G. Russo, G. Zingone, Instability of longitudinal bars in RC columns, J. Struct. Eng. 114 (1988) 445-461.

[58] A. Khajeh, M.M. Attard, Lateral behaviour of concrete, World Acad. Sci. Eng. Technol. 59 (2011) 940-945.

[59] E. Montoya, F.J. Vecchio, S.A. Sheikh, Compression field modeling of confined concrete: constitutive models, J. Mater. Civ. Eng. 18 (2006) 510-517, https:// doi.org/10.1061/(ASCE)0899-1561(2006) 18:4(510).

[60] E. Osorio, J.M. Bairán, A.R. Marí, Lateral behavior of concrete under uniaxial compressive cyclic loading, Mater. Struct. (2012), https://doi.org/10.1617/ s11527-012-9928-9.

[61] J. Pereiro-Barceló, Inestabilidad de barras comprimidas de acero y de SMA en elementos de hormigón fabricados con nuevos materiales, Universitat Politècnica de València,Recomendaciones de diseño. Tesis Doctoral, 2017. 